\title{
LA ESTRUCTURA POLITICA VASCA EN 1983
}

\author{
Francisco José Llera Ramo \\ (Universidad del País Vasco)
}

Comenzaré esta ponencia con una introducción bibliográfica que nos permita situarnos en el contexto de la reflexión científica sobre estos temas en el País Vasco.

Si el desarrollo de la sociología política, y particularmente de la sociología electoral, españolas se puede considerar retardado en relación al nivel que alcanza esta disciplina en la Europa del primer cuarto de siglo y, no digamos nada, respecto al desarrollo experimentado en Norteamérica, en el País Vasco aún nos encontramos en una posición más precaria, muy acoțde, por otra parte, con el desenvolvimiento retardado de otras disciplinas científicas.

El comportamiento político vasco y su sistema de partidos son estudiados normalmente en el conjunto de las obras históricas o retrospectivas de los siglos XVII, XVIII, XIx y comienzos del siglo xx español (Artola, Tuñón de Lara, Martínez Cuadrado, Jutglar, Linz, etc.).

Es el relanzamiento de la cuestión nacional vasca a partir de los años cincuenta-sesenta quien, teniendo como origen el estudio de S. G. Payne, provoca una extensa literatura sobre el surgimiento y desarrollo peculiar de la idea nacionalista, las guerras carlistas, la abolición foral, la lucha de clases, etc., que en los setenta se concretan, entre otros, en los estudios de J. J. Solozábal, E. López Adán, F. Letamendía, A. Elorza, J. Apalategi y los más recientes de J. Corcuera, M. Onaindia, J. Oronoz, G. Jauregui, J. R. Recalde y M. Cruz Mina, así como las obtas no específicamente políticas de L. C. Núñez, La Cámara de Comercio de Bilbao y J. A. Garmen- 
dia. No ba ocurrido lo mismo con la bistoria socio-económica, la del derecho foral o la estructura administrativa, que han tenido un desarrollo mucho más fructífero.

Por el contratio, los estudios de comportamiento político y electoral vascos son mucho más escasos. Refiriéndonos a la Restauración y al período republicano, si exceptuamos las magníficas referencias que J. Corcuera hace en su obra, el breve estudio de I. Estornes y la extensa y documentada sociología electoral de Guipúzcoa de C. Apalategui, nos encontramos que las aproximaciones al hecho electoral vasco son contadas y hechas normalmente desde fueta, como las de Tusell y García Queipo de Llano o la de Linz y De Miguel y siempre referidas al período republicano.

Ha sido la apertura del proceso electoral de la transición democrática quien ha provocado la aparición de una sociología electoral, aunque parcial, más rica. El análisis del sistema de partidos, la geografía y la ecología electotales, aśí como en algunos casos la técnica muestral, están detrás de los ensayos de J. Corcuera y M. A. García, A. Pérez Calvo, R. Cibrián, J. Linz, L. C. Núnez, J. I. Ruiz Olabuénaga, I. Bergareche, Talde, K. Harluxeta, P. Mimiague y J.M. Torrealday, V. Urrutia, J.L. Davant y F. Llera.

Esta breve reseña introductoria, cuya bibliografía detallada se aporta al final de esta trabajo, nos sitúa en el contexto del más reciente desarrollo de la sociología y la ciencia política vascas. Si exceptuamos los estudios históricos y administrativos sobre las instituciones forales y los efectos de su desaparición, así como los análisis históricos o ideológicos sobte el nacionalismo vasco, que se abordan en otra ponencia, casi nada es lo que se ha escrito sobre la institucionalización vasca actual y, como la referencia bibliográfica indica, poco en lo que se tefiere al comportamiento político.

\section{EL CAMBIO ELECTORAL}

EN I.A COMUNIDAD AUTONOMA DEL PAIS VASCO (CAPV) EN 1982

Vamos a movernos aquí a un nivel global, dejando para más adelante el análisis pormenorizado de las comarcas, los municipios y los barrios de las grandes concentraciones metropolitanas, así como de los resultados de encuestas que nos puedan acercar más a las claves explicativas del comportamiento electoral vasco en estos últimos años.

En la CAPV hemos asistido también a una removilización del electorado, que supone todo un récord y que rebasa en casi 5 puntos el máximo del 
$76 \%$ de 1977. Esta removilización es más significativa en el País Vasco que en el conjunto de España, por cuanto las cotas de abstención aquí habían llegado a límites máximos hace sólo dos años.

La abstención vasca afectaba en gran medida a una periferia sociológica formada por población trabajadora, inmigrantes, amas de casa y jóvenes. Esta desmovilización electoral hundía sus raíces, en parte, en la propia marginalidad que les impedia percibir con nitidez los mensajes políticos, el desencanto y la falta de acierto de los políticos para interesar a sectores importantes y, por último, en la disonancia cognoscitiva producida por el mayor volumen y la mayor presencia de la sintonía nacionalista en el discurso político vasco. Efectivamente, la dimensión nacionalista, en sus múltiples ingredientes (anticentralismo difuso, nacionalismo excluyente y agresivo, aacionalismo defensivo y abierto, solidaridad antirrepresiva, etc.), había logrado eclipsar parcialmente Ia dimensión programática e ideológica del discurso conservador/progresista o derecha/izquierda, favorecido especialmente por el ámbito provincial y tegional de las elecciones en que el nacionalismo y la abstención dan su gran estirón.

El hecho de que la abstención se haya incrementado a costa de la mitad de Ios votos que PSOE y UCD habían recibido en 1977 y a costa de los más de cien mil jóvenes que ingresaron en el censo en 1979 , nos da pie para estas observaciones confirmadas por el carácter de aluvión popular y marginal de aquellos electorados en 1977, tal como las encuestas han confirmado.

Indudablemente, este incremento de la participación ha producido una clarificación política de la presencia sociológica de los distintos espacios políticos en nuestro entorno. Al igual que en el conjunto del Estado, supone una mejora de la legitimación de nuesto modelo político, una mayor plausibilidad y un apiñamiento en torno a la defensa de las cotas de libertad alcanzadas.

Sin embargo, el Pás Vasco tiene también algunos matices distintos dada la propia configutación de los espacios y de las dimensiones del discurso político. Por una parte, no existe la homogeneidad en el origen, en el arraigo, en la expresión lingüística y en la identidad histótico-cultural de la mayor parte de las provincias españolas. La heterogeneidad y las discontinuidades sociológicas en nuestra sociedad son evidentes.

En el País Vasco, lejos de la dialéctica de la confrontación entre dos comunidades o dos identidades, que haría suponer la existencia o el predominio de una única dimensión en el discurso político, nos encontramos realmente con dos dimensiones superpuestas, que unas veces se neutralizan y otras se refuetzan recíprocamente.

Al hecho de que en 1977 el $60 \%$ del electorado del PSOE y el $50 \%$ 
del de UCD fuesen inmigrantes o hijos de inmigrantes (frente al $80 \%$ de nativos en el elestorado del PNV o al $65 \%$ de la izquierda abertzale) hay que añadir el dato de que más del $60 \%$ en el PSOE y del $68 \%$ en UCD no pertenecían a ningún tipo de asociación voluntatia o club (cuando en el PNV y la izquierda abertzale se rebasaba ligeramente el $40 \%$ de aisla. cionismo), así como que alrededor del $65 \%$ de aquel electorado no pasaba de los estudios primarios (frente al $40 \%$ y $30 \%$, respectivamente, de los otros) o que los trabajadores etan el $54 \%$ del electorado socialista y el $34 \%$ del centrista (frente al $25 \%$ de los electorados nacionalistas) o que Ias mujeres eran el $64 \%$ del electorado centrista y sólo el $41 \%$ en el socialista en una suerte de intercambio.

No hay lugar, pues, a interpretaciones simplistas, interesadas, de ocasión o para la galería; la cosa es mucho más compleja que decir que unos votan vasco (?) y otros español (?), porque, ¿quién define las esencias?, ¿el Gobierno vasco? Afortunadamente nuestra sociedad es mucho más tica y, si fuese así, no se podría explicar cómo más del $60 \%$ de nuestros ciudadanos se sentían vascos y españoles a la vez en una reciente encuesta y, por supuesto, se ubicaban no sólo entre los antiguos electores del PSOE, UCD, AP o el PCE, sino también en los propios electorados nacionalistas.

Veamos, por tanto, cómo se autoubican los propios ciudadanos vascos en esta doble dimensión (derecha/izquierda, nacionalista/no nacionalista) a partir de una escala de 2 a 9 puntos. Veamos la siguiente tabla:

\section{TABLA 1}

Distribuciones de Ia autoubicación de los entrevistados de la Comunidad Autónoma Vasca en las escalas de nacionalismo e izquierda/derecha en 1982

\begin{tabular}{lrrrrrrrrrrrr}
\hline & 2 & 3 & 4 & 5 & 6 & 7 & 8 & 9 & $N S$ & $N C$ & $\%$ & $N$ \\
\hline Nacionalismo & 13 & 5 & 5 & 9 & 19 & 12 & 10 & 12 & 8 & 7 & 100 & 5.389 \\
Derecha/izquierda & 1 & 1 & 3 & 10 & 21 & 21 & 15 & 9 & 19 & 9 & 100 & 5.389 \\
\hline
\end{tabular}

La posición 2 sería la de los que no son nacionalistas ni regionalistas y se sienten radicaimente de derecha, destacando mucho más por la primera dimensión (13\%) que por la segunda (1\%). Las posiciones 3 y 4 agrupadas serían las de regionalismo moderado $(10 \%)$ y de derecha conservadora $(4 \%)$, destacando más por lo primero que por lo segundo. Las opciones 5 y 6 serían las de los regionalistas convencidos y nacionalistas moderados $(28 \%)$, que se equipararía a posiciones de centro derecha y 
TABLA 2

Evolución electoral de la Comunidad Autónoma Vasca entre 1977 y 1982 $280.828 \mathrm{M}-83$

\begin{tabular}{|c|c|c|c|c|c|c|c|c|c|}
\hline & \multicolumn{3}{|c|}{ EG.Jn } & \multicolumn{3}{|c|}{ EG-M79 } & \multicolumn{3}{|c|}{ EP-A79 } \\
\hline & Votos & $\begin{array}{c}\% \\
\text { Censo }\end{array}$ & $\begin{array}{l}\% \\
\text { V.V. }\end{array}$ & Votos & $\begin{array}{c}\% \\
\text { Censo }\end{array}$ & $\begin{array}{l}\% \\
V . V .\end{array}$ & Votos & $\begin{array}{c}\% \\
\text { Censo }\end{array}$ & $\begin{array}{c}\% \\
V . V .\end{array}$ \\
\hline PNV & 290.000 & 21,3 & 28,8 & 277.000 & 17,7 & 27,5 & 349.000 & 22,3 & 36,9 \\
\hline $\mathrm{HB}$ (ANV/ESB) & 43.000 & 3,2 & 4,3 & 152.000 & 9,7 & 15,1 & 186.000 & 11,9 & 19.7 \\
\hline $\begin{array}{l}\mathrm{EE} \\
\mathrm{ESEI}\end{array}$ & 63.000 & 4,6 & 6,3 & 80.000 & 5,1 & 7,9 & 69.000 & 4,4 & 7,3 \\
\hline TOTAI. NACTONALISTAS & 396.000 & 29,1 & 39,3 & 509.000 & 32,5 & 50,5 & 604.000 & 38,6 & 63,9 \\
\hline $\begin{array}{l}\text { PSE (PSP) } \\
\text { UCD/AP/PDP/PDL }\end{array}$ & 283,000 & 20,8 & 28,1 & 192.000 & 12,2 & 19,1 & 247.000 & 9,4 & 15,6 \\
\hline $\begin{array}{l}+\mathrm{DCV} \\
\cos \end{array}$ & 246.000 & 18,1 & 24,4 & 204.000 & 13 & 20,3 & 115.000 & 7.4 & 12,2 \\
\hline PCE & 46.000 & 3,3 & 4,6 & 47,000 & 3 & 4,7 & 42.000 & 2,7 & 4.4 \\
\hline OTROS & 36.000 & 2,6 & 3,6 & 55.000 & 3,5 & 5,5 & 37.000 & 2,3 & 3,9 \\
\hline Total Estatales & 612.000 & 44,9 & 60,7 & 498.000 & 31,7 & 49,5 & 341.000 & 21,8 & 36 \\
\hline $\begin{array}{l}\text { TOTAL CENTRO-DER, } \\
\text { TOTAL IZQUIERPA }\end{array}$ & $\begin{array}{l}538.000 \\
470.000\end{array}$ & $\begin{array}{l}39,5 \\
34.5\end{array}$ & $\begin{array}{l}53,4 \\
46,6\end{array}$ & $\begin{array}{l}494.000 \\
513.000\end{array}$ & $\begin{array}{l}31,5 \\
32,7\end{array}$ & $\begin{array}{l}49,1 \\
50,9\end{array}$ & $\begin{array}{l}464.000 \\
481.000\end{array}$ & $\begin{array}{l}29,6 \\
30,7\end{array}$ & $\begin{array}{l}49,1 \\
50,9\end{array}$ \\
\hline $\begin{array}{l}\text { VotaNTES } \\
\text { CENSO ELLCTORAL }\end{array}$ & $\begin{array}{l}1.042 .000 \\
1.363 .377\end{array}$ & $\begin{array}{l}76,4 \\
200\end{array}$ & 100 & $\begin{array}{l}1.033 .000 \\
1.567 .437\end{array}$ & $\begin{array}{l}65,9 \\
100\end{array}$ & 100 & $\begin{array}{r}970.000 \\
1.567 .437\end{array}$ & $\begin{array}{l}62,8 \\
100\end{array}$ & 100 \\
\hline
\end{tabular}

\begin{tabular}{|c|c|c|c|c|c|c|c|c|}
\hline & \multicolumn{3}{|c|}{ ER-M\&0 } & \multicolumn{3}{|c|}{ EG-082 } & \multicolumn{2}{|c|}{$\begin{array}{l}\text { Balance } \\
\text { (mites) }\end{array}$} \\
\hline & Votos & $\stackrel{\%}{\text { Cienso }}$ & $\begin{array}{c}\mathscr{q} \\
V . V .\end{array}$ & Votos & $\begin{array}{c}\% \\
\text { Censo }\end{array}$ & $\begin{array}{c}\% \\
V . V .\end{array}$ & $\begin{array}{l}\text { Dif. } \\
79 / 82\end{array}$ & $\begin{array}{l}\text { Dif. } \\
80 / 82\end{array}$ \\
\hline PVN & 349.102 & 22 & 38 & 380.983 & 25,1 & 32 & +104 & +32 \\
\hline $\mathrm{HB}$ (ANV/ESB) & 151.636 & 9,6 & 16,5 & 176.117 & 11,6 & 14,8 & +24 & +25 \\
\hline $\mathrm{EE}$ & 89.953 & 5,7 & 9,8 & 92.219 & 6,1 & 7,7 & +12 & +2 \\
\hline ESEI & 8.280 & 0,5 & 0,9 & & & & & \\
\hline TOTAL NACIONALYSTAS & 598.971 & 37,8 & 65,2 & 649.319 & 42,8 & 54,5 & +140 & +50 \\
\hline $\begin{array}{l}\text { PSE (PSP) } \\
\text { UCD/AP/PDP/PDL }\end{array}$ & 130.221 & 8,2 & 14,2 & 349.531 & 23 & 29,4 & +157 & +219 \\
\hline$+\mathrm{DCV}$ & 121.846 & 7,7 & 3,3 & 138.984 & 9,2 & 11,7 & -65 & +17 \\
\hline CDS & & & & 22.123 & 1,5 & 1,9 & & \\
\hline PCE & 36.845 & 2,3 & 4 & 21.071 & 1,4 & 1,8 & -26 & -16 \\
\hline Orros & 30.392 & 1,9 & 3,3 & 10.776 & 0,7 & 0,9 & -44 & -19 \\
\hline TOTaL ESTATALES & 319.304 & 20,1 & 34,8 & 542.491 & 35,7 & 45,5 & +44 & $+\mathbf{2 2 3}$ \\
\hline TOTAL CENTRO-DER. & 472.414 & 29,8 & 51,4 & 543.875 & 35,8 & 45,6 & +50 & +72 \\
\hline TOTAL, IZOULRRDA & 445.861 & 28,1 & 48,6 & 647.935 & 42,7 & 54,4 & -135 & $\div 202$ \\
\hline Vorantes & 932.371 & 58,8 & 100 & 1.223 .199 & 80,6 & 100 & +190 & +291 \\
\hline CENSO EIECTORAL & 1.584 .577 & 100 & & 1.518 .402 & 100 & & & \\
\hline
\end{tabular}


«Papers»: Revista de Sociologia

\section{Gráfrco 1}

Evolución de las tendencias ideológicas en la C.A.V. desde 1977

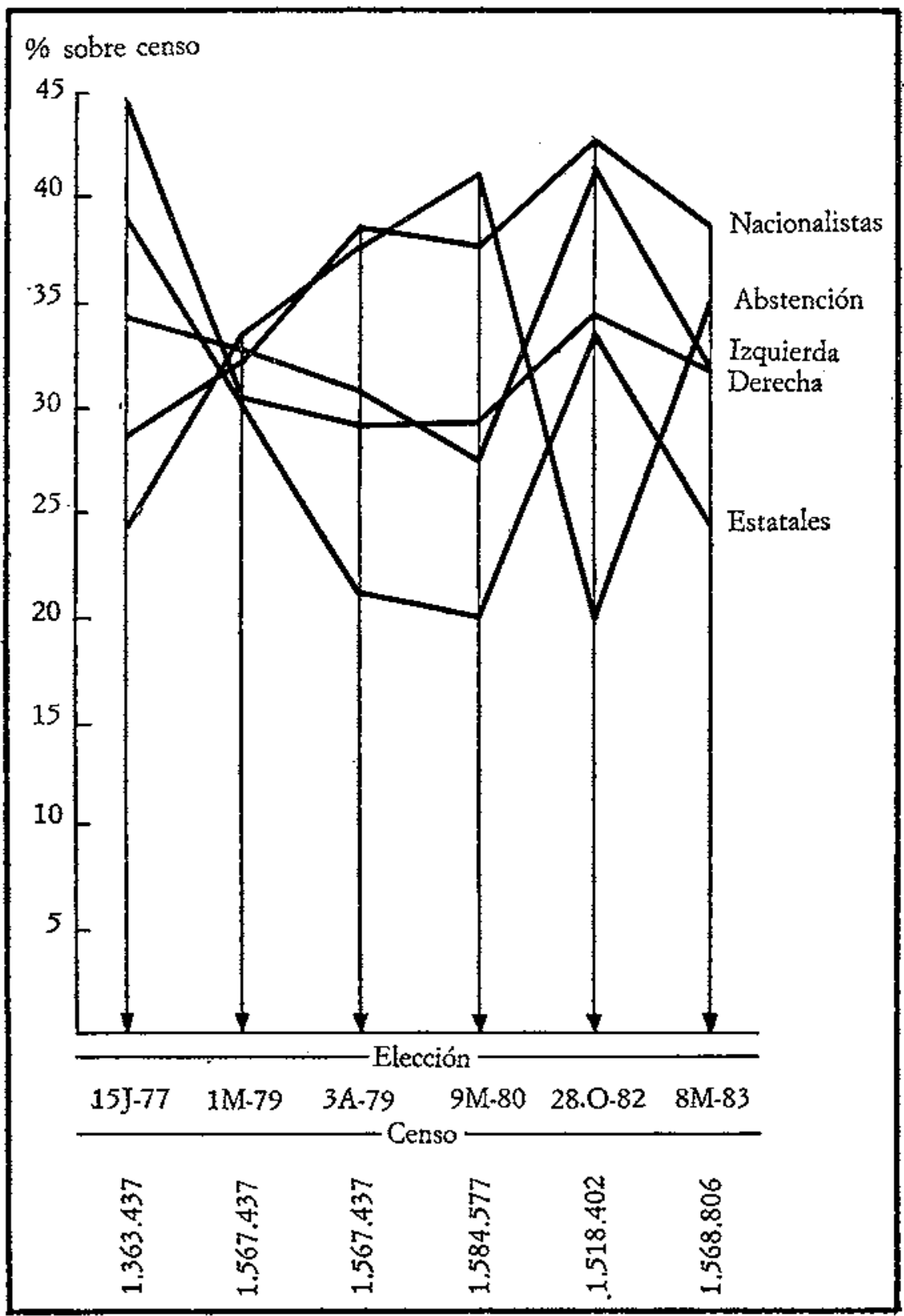


La estructura política vasca en 1983

GRÁFICO 2

Evolución del sistema de partidos electorales en la CAV desde 1977

$\%$ sobre censo

25

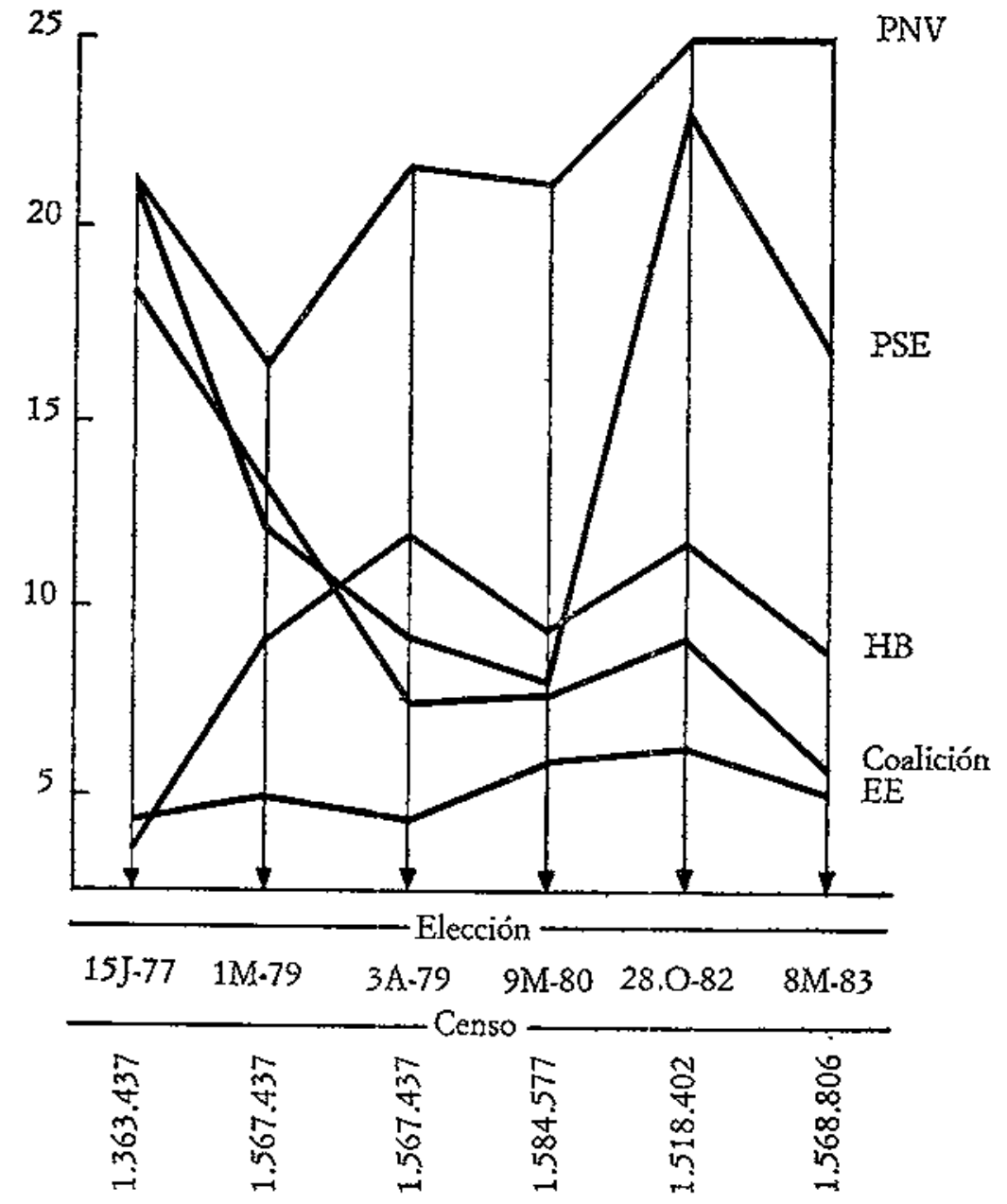


centro izquietda ( $31 \%$ ). Las posiciones 7 y 8 serían las de los naciona listas convencidos $(22 \%)$ y, en mayor medida, las de las posiciones de la izquierda moderada (36\%). Finalmente, la posición 9 sería la de los nacionalistas radicales (12\%), teforzada por la izquierda radical ( $9 \%$ ).

Esta estructura ideológica previa (mayo de 1982) se corresponde con to acaecido en el proceso electoral reciente y no se puede tomat una única dimensión para explicar los resultados.

A diferencia de lo ocurrido en el conjunto del Estado, en la CAPV no se ha producido la misma centrifugación del centro. Por el contrario, se refuerzan tanto el centrismo reformista del nacionalismo moderado representado por el PNV como el socialismo moderado tepresentado por el partido ganador en el conjunto del Estado, que aglutinan entre ambos el $60 \%$ de los votantes y casi el $50 \%$ del electorado, con la particularidad de detentat respectivamente los gobiernos autónomo y central. El cambio, por tanto, ha sido centrípeto en nuestro caso.

No obstante, se mantiener firmes las posiciones tanto de la derecha no nacionalista como de la izquierda nacionalista, que mantienen en sus términos anteriores la distancia ideológica de nuestro sistema de partidos, aunque reducen parcialmente su fragmentación polarizada.

\section{EL SISTEMA DE PARTIDOS RESULTANTE: LA NUEVA CORRELACION DE FUERZAS}

Como podemos ver en la tabla II, nos encontramos ante un sistema muy equilibrado de partidos parlamentarios que se teparten seis espacios políticos: 3 conservadores (PNV, UCD y AP) y 3 de cambio (PSOE, HB y EE), a los que hay que añadit 2 partidos colaterales (CDS y PCE) $\sin$ representación parlamentaria.

Teniendo en cuenta la dimensión nacional de su discurso político, nos encontramos también con el mismo equilibrio de 6 espacios: 3 nacionalistas (PNV, HB y EE) y tres estatales (PSOE, UCD y AP).

En cualquiera de las dos cootdenadas hay una mayoría ajustada: una mayoría nacionalista de casi el $55 \%$ de los votas $(43 \%$ del electorado) y una mayoría de izquierda también del $55 \%$ de los votantes $(43 \%$ del electorado).

Por otra parte, en cualquiera de las dos dimensiones nos encontramos con una hegemonía clara: la del PNV, con el $59 \%$ del voto nacionalista y con el $70 \%$ del voto conservador, y la del PSOE, con el $64 \%$ del voto estatal y el $54 \%$ del voto de izquierda. 
De este modo, mientras que la distribución interna de los espacios nacionalistas y conservador se encuentra prácticamente congelada desde las elecciones provinciales de 1979 , el gtan cambio se produce en el reparto del espacio de izquierda, en el que se reduce ostensiblemente la fragmen. tación de 1980 y se refuerzan las posiciones moderadas de ámbito estatal, retornando a la cortelación de fuerzas de partida en 1977.

En el gráfico 1 tenemos la evolución de los distintos bloques en estos últimos cinco años. Si el incremento de la abstención fue el tesponsable del cambio de la correlación de fuetzas a partir de 1979, la reducción de aquélla supone una reestructuración de ésta:

- El nacionalismo ha conseguido ahora su cota más alta tanto en términos absolutos como relativos, habiendo sido la última fuerza en 1977 y consolidando su primera posición desde abril de 1979.

- La izquierda bate también su propio récord igualando al nacionalismo, invirtiendo su tendencia sistemáticamente descendente desde 1977 en que ocupaba un tercer lugar.

- La derecha se convierte en la tercera fuerza, asegurando la inflexión recuperadora iniciada en 1980 y mejorando ligerísimamente sus primeros resultados de 1977, pasando del segundo al tercer lugar.

- Sin embargo, los partidos de ámbito estatal no logran alcanzar su cota de 1977, en que partieron del ptimer puesto para caer en picado al último puesto en 1979 y 1980 , recuperándose en los comicios del día 28.

A pesar de todo, el nacionalismo encarnado por el PNV se mantiene como predominante por la mayor impregnación nacionalista del tejido social y su mayor capacidad de movilización, así como por su control institucional. Por otra parte, el rupturismo antisistema del principal representante de la izquierda nacionalista resta fuerza a la izquierda en su conjunto, como las experiencias municipal y provincial demuestran.

\section{EL CAMBIO PARTIDO A PARTIDO}

En el gráfico 2 tenemos la evolución del sistema de partidos parlamentarios a través de las distintas elecciones competitivas. En la tabla 2 tenemos, por otro lado, los datos absolutos y relativos partido a partido en esos mismos procesos electorates.

El PNV después del bache de marzo de 1979, en que había perdido 13.000 votos, recuperándolos con creces en las elecciones provinciales de ese mismo año y estancándose en la cota de 349.000 votos en 1980 , telanza 
su primera posición subiendo akora otros 32.000 votos, alcanzando su cota más alta de 381.000 votos, representando a una cuarta parte del electozado y a casi un tercio de los votantes.

El PSOE, que partió de un segundo puesto a estrecha distancia del PNV y cayó en picado a partir de las segundas elecciones generales de 1979 , llegando a perder para 1980 más de la mitad de su clientela, vuelve ahora al segundo puesto pisándole los talones al PNV y superando en 66.000 nuevos electores su cota inicial de 283.000 votos, para representar a un $23 \%$ del electorado y a un $29 \%$ de los votantes.

La común trayectoria decadente de los pattidos de centro y derecha estatales (UCD, DCV, DIV, IFPV, AP), ahora coaligados bajo las siglas $\mathrm{UCD} / \mathrm{AP} / \mathrm{PDP} / \mathrm{PDL}$, ni logra recuperar su tercera posición inicial ni la mitad del electorado perdido para abril de 1979 , aunque a partir de esta fecha inicia una lenta línea ascendente que le coloca en este momento en la cuarta posición, representando a un $9 \%$ del electorado y a un $12 \%$ de Los votantes.

La coalición Herri Batasuna, tras el bache sufrido en 1980 en que pierde 35.000 votos respecto de las elecciones provinciales de abril de 1979 , recupera en estos dos últimos años una parte (25.000 votos), proveniente probablemente de los más de 17.000 votos que solían recabar EMK y LKI, que en estas últimas elecciones han recomendado el voto para la coalición $\mathrm{HB}$, no logrando, pot tanto, batir su récord de abril de 1979 y representando en este momento al $12 \%$ del electorado y al $15 \%$ de los votantes.

Euskadiko Ezkerra ha vuelto a batir su propio récord de 1980, situándose en los 92.000 votos y consolidando su línea ascendente y su espacio político como cuarta fuerza política (una vez desmembrada la coalición $\mathrm{UCD} / \mathrm{AP} / \mathrm{PDP} / \mathrm{PDL})$, que representa al $6 \%$ del electorado y al $8 \%$ de Ios votantes, pudiendo convertirse en átbitro de la situación en un sistema de mayorías de tres partidos, ya sean nacionalistas o de izquierdas, por compaginar ambas dimensiones y por su carácter institucional frente a las posiciones antisistema.

Para terminat, el CDS del ex presidente Suárez tiene una presencia totalmente residual compartida con el PCE, que ha perdido más de la mitad de su electorado desde 1977, al igual que ha sucedido con todos los partidos minoritarios, no representando entre todos ni al $4 \%$ del electorado o al $5 \%$ de los votantes.

El mensaje de cambio progresista, mezclado con el carisma de Felipe y el arrastre del triunfo en Madrid, ha engatusado al mayor contingente de electores al removilizar para el PSOE casi 160.000 votos con respecto a 1979 y más de 200.000 con respecto a 1980 . 
El discurso globalizante, conservador y de resultados del partido del gobierno autonómico ha revalidado la gestión del lebendakari al tecoger 30.000 nuevos votos desde 1980 y más de 100.000 con respecto a las elecciones generales de 1979.

Contener el desgaste del discutso antisistema y de la resistencia rupturista es lo que ha hecho HB tras el liderazgo de ETA, al recuperar algo más de 20.000 votos procedentes fundamentalmente de la izquierda radical representada por LKI y EMK.

$\mathrm{Ni}$ el atractivo liderazgo de Bandrés, ni la fusión de EIA y el EPK de Lertxundi, ni la vía de una pacificación negociada, ni el discurso contemporizador de la campaña han lanzado al estrellato a la izquierda vasca propugnada por $\mathrm{EE}$, que ha congelado su posición y su espacio político.

En definitiva, al igual que en el testo de España, el síndrome del cambio y del voto útil también se ha dado entre nosotros, inclinándose por el PNV una pequeña parte del electorado volátil centrista de clase media, mientras que la mayor parte del voto popular removilizado entre obreros e inmigrantes lo ha hecho por el PSOE y el voto joven e intelectual se ha repartido mayoritariamente entre las tres opciones de izquierda.

\section{EL CAMBIO ELECTORAL EN LA COMUNIDAD FORAL DE NAVARRA (CFN)}

En la tabla 3 se puede observar cómo la izquierda ha superado en casi 30.000 votos sus mejores resultados de $1977 \mathrm{y}$ el nacionalismo ha multiplicado por tres esos mismos efectivos electorales confirmando su ten dencia ascendente. Por otra parte, el hecho de que sean el PSOE y las tendencias nacionalistas moderadas las que más han incrementado sus votos en sus respectivos bloques puede suponer mejores condiciones para plan. tear el problema de las rejaciones entre la Comunidad Autónoma Vasca y la Comunidad Foral de Navarra.

La correlación de fuerzas es claramente distinta a la de la Comunidad Autónoma Vasca, como indica el gráfico 3. Las fuerzas políticas estatales siguen siendo mayoritarias $(74 \%)$ entre el electorado, una vez temontado el declive de 1979 , si bien no logran alcanzar los más de 240.000 votos de partida en 1977. En este bloque, aunque el PSOE es mayoritatio (48\%), se han producido grandes cambios, dejando de set el centrismo modetado la primera fuezza en todas las elecciones para pasar al tercer puesto al ser aventajada en esta ocasión por la derecha navarrista representada por UPN/AP, que tepresenta el $32 \%$ del voto estatal frente al $13 \%$ de UCD. 
TABLA 3

Evolución electoral de la Comunidad Foral de Navarra entre 1977 y 1982

\begin{tabular}{|c|c|c|c|c|c|c|c|c|c|c|c|c|c|c|}
\hline & \multicolumn{3}{|c|}{ EG-377 } & \multicolumn{3}{|c|}{ EG-M79 } & \multicolumn{3}{|c|}{ EF-A79 } & \multicolumn{3}{|c|}{ EG-O82 } & \multicolumn{2}{|c|}{ Balance (miles) } \\
\hline & Votos & $\begin{array}{c}\% / 6 \\
\text { Censo }\end{array}$ & $\begin{array}{c}\% \\
V . V .\end{array}$ & Votos & $\begin{array}{c}\% \\
\text { Censo }\end{array}$ & $\begin{array}{c}9 \% \\
v . v .\end{array}$ & Votos & $\begin{array}{c}\% \\
\text { Censo }\end{array}$ & $\begin{array}{c}\% \\
V . V .\end{array}$ & Votos & $\begin{array}{c}95 \\
\text { Censo }\end{array}$ & $\begin{array}{c}\% \\
V . V .\end{array}$ & $\begin{array}{c}\text { Dif. } \\
M 79 / 82\end{array}$ & $\begin{array}{c}\text { Dif. } \\
\text { A79/82 }\end{array}$ \\
\hline PSOE (+ PSP) & 61.822 & 19,4 & 23,8 & 55.910 & 15,4 & 22 & 48.289 & 13,3 & 19 & 112.639 & 30 & 38,1 & +56 & +64 \\
\hline UCD & 75.255 & 23,5 & 29 & 84.041 & 23,1 & 33 & 68.040 & 18,7 & 26,8 & 31.223 & 8,3 & 10,6 & -53 & -37 \\
\hline CDS & & & & & & & & & & 12.309 & 3,3 & 4,2 & & \\
\hline UPN (AFN, AP) & 21.884 & 6,9 & 8,4 & 28.460 & 7,8 & 11,2 & 40.764 & 11,2 & 16,1 & 76.354 & 20,3 & 25,8 & +48 & +36 \\
\hline P. CARLISTA & 8.357 & 2,6 & 3,2 & 19.850 & 5,5 & 7,8 & 12.165 & 3,3 & 4,8 & & & & & \\
\hline PCE & 6.294 & 2 & 2.4 & 5.658 & 2,6 & 2,2 & 6.231 & 1,7 & 2,5 & 2.155 & 0,6 & 0,7 & -3 & -4 \\
\hline UNAI & 24.868 & 7,8 & 9,8 & 11.038 & 3 & 4,3 & 7.419 & 2 & 2,9 & & & & & \\
\hline OtROS & 42.563 & 13,3 & 16,4 & 5.473 & 1,5 & 2,1 & 1.979 & 0,5 & 0.8 & 1.501 & 0,4 & 0,5 & -4 & $-0,5$ \\
\hline TOTAL ESTaTaLES & 241.043 & 75,4 & 93 & 210.430 & 57,9 & 82,7 & 184.887 & 50,8 & 72,8 & 236.181 & 62,8 & 79,9 & +26 & +49 \\
\hline CANDIDAT. UNITAR. & & & & & & & 27.901 & 7,7 & 11 & & & & & \\
\hline HB & & & & 22.636 & 6,2 & 8,9 & 28.234 & 7,8 & 11,1 & 34.769 & 9,3 & 11,8 & +12 & +6 \\
\hline UAN (NV) & 18.216 & 5,7 & 7 & 21.532 & 5,9 & 8,5 & 6.727 & 1.8 & 2,6 & & & & & \\
\hline PNV & & & & & & & 6.118 & 1,7 & 2,4 & 16.315 & 4,3 & 5,5 & & +10 \\
\hline $\mathrm{EE}$ & & & & & & & & & & 8.398 & 2,2 & 2,8 & & \\
\hline TOTAL NACTONALISTA & 18.216 & $5, \gamma$ & 7 & 44.168 & 12,1 & 17,3 & 41.079 & 11,3 & 16,2 & 59.482 & 15,8 & 20,1 & +15 & +18 \\
\hline TOTAL CENTRO-DER. & $\$ 25.810$ & 39,4 & 48,5 & 134.247 & 36.9 & 52,7 & 121.649 & 33,4 & 47,9 & $\mathfrak{1} 36.654$ & 36,3 & 46,2 & +29 & +15 \\
\hline TOTAL IZQUIERDA & 133.449 & 41,8 & 51,5 & 120.351 & 33,1 & 47,3 & 132,218 & 36,4 & 52,1 & 159.009 & 42,3 & 53.8 & +39 & +27 \\
\hline VOTANTES & 263.896 & 82,7 & 100 & 259.412 & 71,3 & 100 & 258.236 & 71 & 100 & 306.353 & 81,5 & 100 & $\therefore 47$ & +48 \\
\hline CENSO EIECTORAL & 319.222 & 100 & & 363.713 & 100 & & 363.713 & 100 & & 375.876 & 100 & & +12 & +12 \\
\hline
\end{tabular}




\section{GrÁfICO 3}

Evolución del sistema de partidos en Navarra (\% sobre censo)

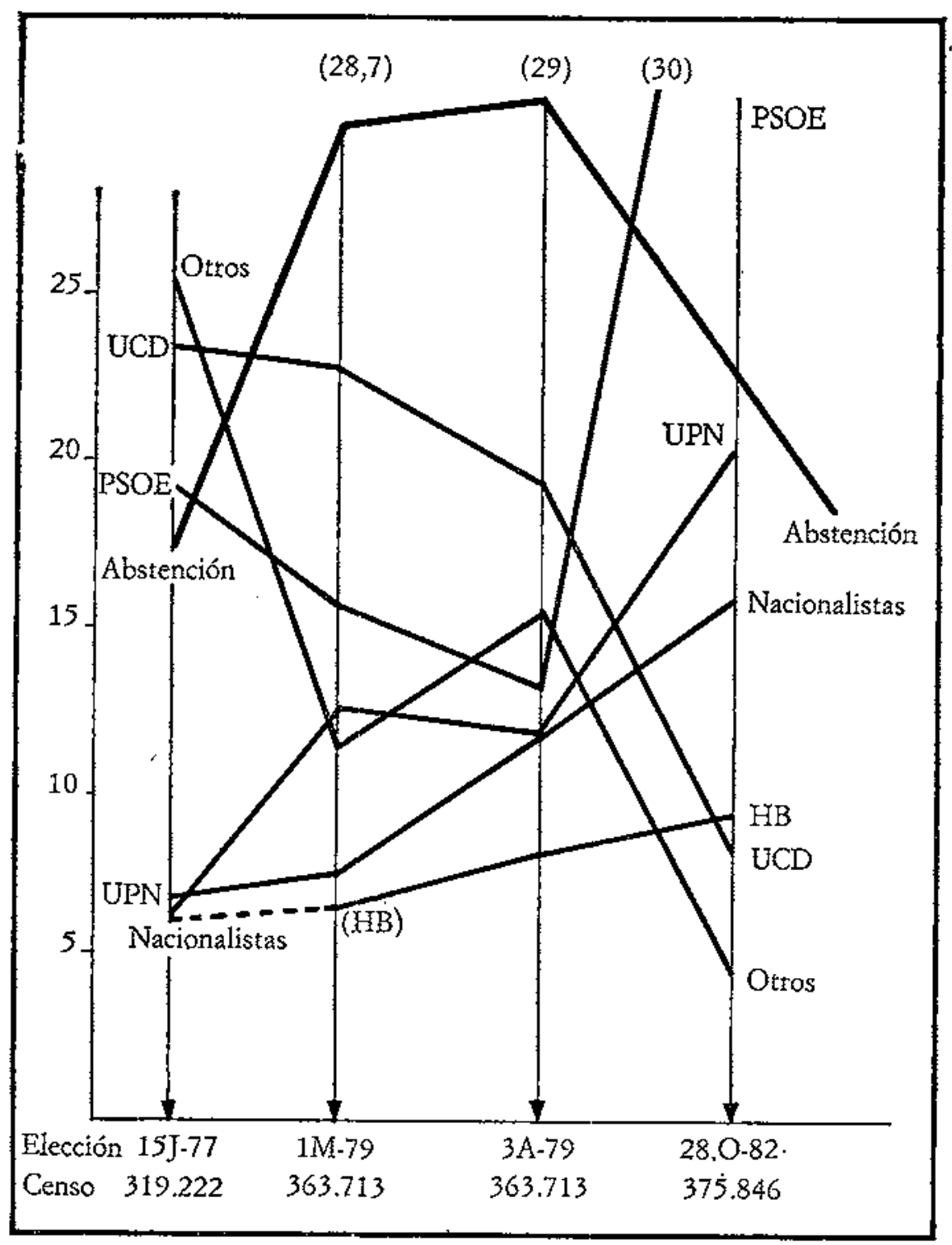


La izquierda con 159.000 votos bate su propio récord de partida fijado en 133.000 votos en 1977 y revalidado en las Elecciones Forales de 1979. Casi tres cuartas partes del voto de izquierda pertenecen al PSOE y, a continuación, como en la Comunidad Autónoma Vasca, Ia segunda fuerza de la izquierda $(22 \%)$ es $\mathrm{HB}$, situándose a continuación EE y el PCE.

Las opciones de centro-derecha describen una serie de pequeños altibajos en los distintos procesos electorales, pero se mantienen alrededor de los 130.000 votos, que representan el $36 \%$ del electorado navarro y el $46 \%$ de los votantes. Con todo, lo más importante, como ya hemos apuntado, es el cambio de hegemonía en este bloque, pasando de UCD (con el $60 \%$ de los votos de centro y derecha en 1979) a UPN/AP, que cuenta en este momento con el $56 \%$ del voto conservador.

La centrifugación del centro se ha producido también en Navarra, a diferencia de lo ocurrido en la Comunidad Autónoma Vasca, pero con la particularidad de que aquí, además del componente conservador de la derecha representada por UPN, hay que destacar el navarrismo distanciador del nacionalismo vasco.

El nacionalismo vasco también bate su propio récord al rondar los 60.000 votos, representando a un $16 \%$ del electorado navarro, habiendo avanzado conjuntamente las posiciones moderadas (PNV y EE) más que el nacionalismo radical de $\mathrm{HB}$, si bien esta coalición, a diferencia de la Comunidad Autónoma Vasca, es la fuerza hegemónica en este bloque con el $58 \%$ del voto nacionalista, repartiéndose el resto el PNV $(27 \%)$ y EE $(15 \%)$.

Consecuentemente, el sistema de partidos navarro es mucho más complejo y crítico que el de la Comunidad Autónoma Vasca. Si tuviésemos que formar una coalición parlamentaria que representase a la mayoría absoIuta de los votantes, éstas serían las coaliciones improbables: con dos partidos sólo la alcanzan el PSOE (38\%) y UPN $(20 \%)$ y con tres tendríamos - una coalición de izquierda formada por PSOE $+\mathrm{HB}(12 \%)+\mathrm{EE}$ (3\%) o una coalición centrista formada por PSOE + UCD $(11 \%)+$ $+\operatorname{CDS}(4 \%) \%$, finalmente, una coalición centrista también, pero con ingredientes nacionalistas, formada por el propio PSOE + UCD + PNV $(5 \%)$.

Así pues, en conjunto podemos decir que Navarta es tan de izquierda como la Comunidad Autónoma Vasca, aunque el socialismo moderado estatal del PSOE detenta, además de un mayor peso en el conjunto de la izquierda, la primera posición en el sistema de partidos navarros. La izquierda nacionalista, por su parte, tiene un peso sociológicamente más importante que en la propia Comunidad Autónoma Vasca. El arrastre del PSOE se ha producido en Navarra al igual que en toda España, pero sin componente inmigrante como en las otras provincias. 
Por otra parte, en Navarta la centrifugación del centro supone un endurecimiento del conservadurismo navartista, que incrementa su fuerza y endurece su discurso político, algo de lo que no está exenta la Comunidad Autónoma Vasca desde la coalición centro-derechista.

Esto, unido al peso del nacionalismo radical y al hecho de que no se haya reducido la fragmentación, sigue planteando en Navarra un sistema de partidos mucho más polarizado y con un distanciamiento ideológico muy fuette, que sólo la moderación y la capacidad de concertación socialista pueden reconducir, al situarse Navarta en el corazón del problema de la pacificación de Euskadi.

\section{EL MAPA COMARCAL}

DE LAS COMUNIDADES AUTONOMA DEL PATS VASCO $Y$ FORAL DE NAVARRA

Reduciendo toda la información anterior a una lectura de grandes coordenadas del mapa comarcal de ambas comunidades, se pueden deducir las siguientes conclusiones:

1. Al igual que en 1979 , se puede trazar un flujo o anillo entre las distintas áreas metropolitanas con pilates en las bolsas urbano-industriales y de inmigración: San Sebastián, zona industrial del Deva Medio, Duran. guesado, Gran Bilbao, zona industrial del Valle de Ayala, Vitoria, zona industrial de la Barranca y Área Metropolitana de Pamplona, que desctibirían otras tantas situaciones de alta fragmentación electoral e intercambio de las posiciones dominantes, así:

- Relativa equiparación de la mayoría absoluta nacionalista y de iz. quierda y predominio compartido del PNV y el PSE desde el Área Metropolitana de San Sebastián hasta el Valle de Ayala.

- Clara hegemonía de la izquierda y predominio del PSE-PSOE desde el Area Metropolitana de Vitotia hasta la de Pamplona, siendo el PNV el competidor en la primera y UPN en la segunda.

2." Hegemonía nacionalista y hegemonía o predominio del PNV decrecientes desde las zonas circundantes, interiores o costeras a este flujo y las zonas norte de Alava y Navarra donde, si bien el nacionalismo no logra ser hegemónico, al menos es mayoritario. 
Mapa comarcal de las elecciones de 1982 en la CAPV y la CFN

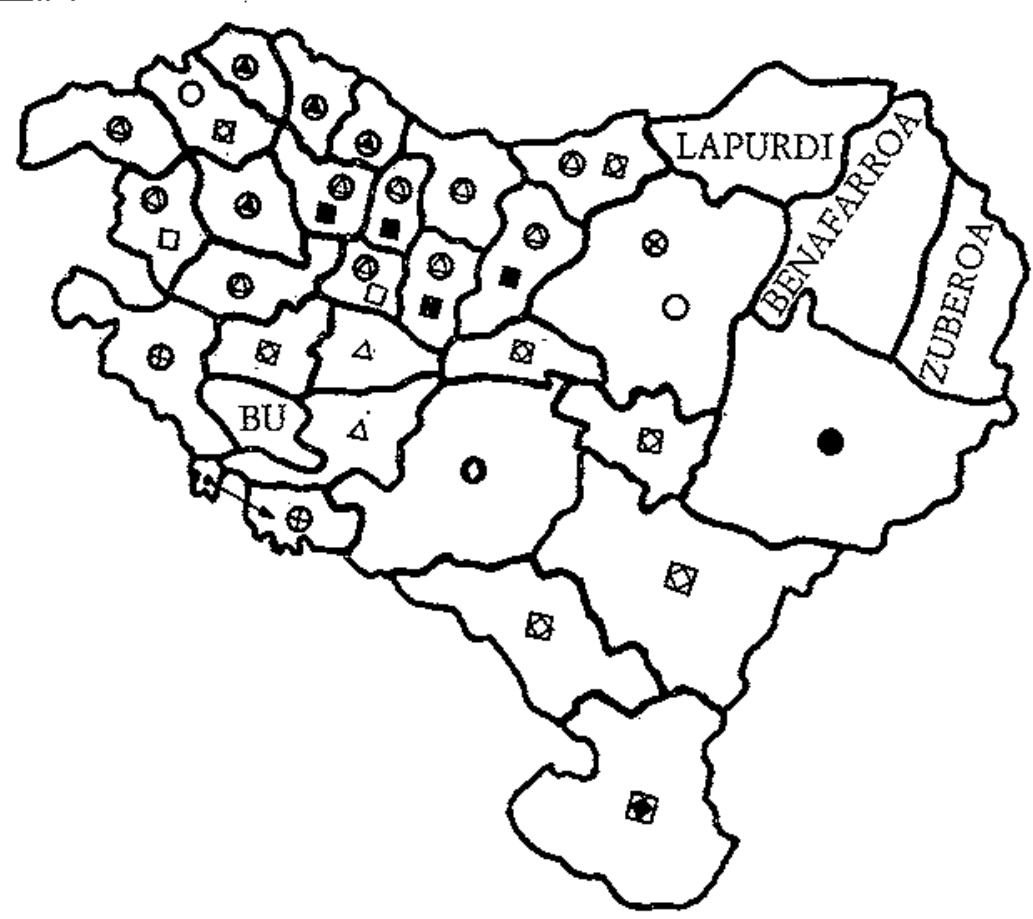

Q Mayoría absoluta nacionalista y PNV partido con mayoría absoluta.

- Mayoría absoluta nacionalista y PNV mayoritario.

Q Mayoría absoluta de izquierda y PSE mayoritario.

- Mayoría absoluta de izquierda.

Q Partido Mayoritario UPN.

- Mayoría absoluta centro-derecha estatal y UPN mayoritario.

$\triangle$ Partido mayotitario PNV.

O Nacionalismo rondando la mayoría absoluta.

$\square$ Izquierda rondando la mayoría absoluta.

$\oplus$ Partido mayoritario la Coalición.

- Mayoría absoluta centro-estatal y PSOE mayoritario.

Mayoría absoluta de izquierda y PSOE con mayoría absoluta. 
3. Mayor peso del nacionalismo moderado al noroeste de este flujo (máximo del $57 \%$ de los votos válidos del PNV en la comarca vizcaína de Uribe Costa), frente a la mayor presencia del nacionalismo radical al nordeste del mismo en la Barranca navarra y el Goiherri guipuzcoano (donde Herri Batasuna supera el $20 \%$ de los votos válidos).

4. Dualismo electoral diferenciado en las periferias alavesa y navarra:

- Predominio centro-derecha sobre el nacionalismo y la izquierda en Álava.

- Hegemonía del centto y la derecha y predominio UPN en la Navarra pirenaica, así como progresivo predominio de la izquierda y del PSOE a costa del centro-derecha, hasta conseguir la hegemonía en la Ribera Oriental.

\section{EL PODER LOCAL EN 1983}

En la tabla 4 tenemos la evolución electoral de la CAV en tres momentos: las elecciones provinciales de 1979 y 1.983 y las últimas elecciones generales de 1982. La comparación entre las dos primeras es obvia, mientras que la introducción en este análisis de las elecciones del 1982 se hace para calibrar la estabilidad o permanencia de los cambios tan significativos que entonces se habían producido en el País Vasco.

Las conclusiones que se pueden sacar de su lectura son claras:

El PNV vuelve a ser el primer partido de la CAV y Navarra conjuntamente, y es el único que incrementa sus votos con respecto a ambas elecciones: más de 40.000 en relación a 1979 y unos 13.000 desde octubre, si a los 11.000 de la CAV añadimos los 2.000 de Navatra. Aunque no sea importante el incremento como tal, lo es el hecho de que sea, junto con el PCE, el único partido que no pierde votos en todo el Estado desde las elecciones generales de 1982. Por otra parte, es interesante el teparto de estos incrementos con respecto a octubre: pueden ser significativos los 13.000 votos recuperados en Alava y el estancamiento de Guipúzcoa $(+1.000)$, Navarra $(+2.000)$ y Vizcaya $(-3.000)$. Así, si consideramos las 18 poblaciones mayores de 20.000 habitantes de la CAV (el $80 \%$ de la población alavesa, el $75 \%$ de la vizcaína y el $56 \%$ de la guipuzcoana), el PNV gana votos en Vitoria (11.000), Llodio, Rentería, Baracaldo, Ba- 
TABLA 4

Evolución electoral de la Comunidad Autónoma Vasca en 1979, 1982 y 1983

\begin{tabular}{|c|c|c|c|c|c|c|c|c|c|c|c|}
\hline & \multicolumn{3}{|c|}{ EM-1979 } & \multicolumn{3}{|c|}{ EG-1982 } & \multicolumn{3}{|c|}{ EM-1983 } & \multicolumn{2}{|c|}{ Balance } \\
\hline & Votos & $\begin{array}{c}\% \\
\text { Censo }\end{array}$ & $\begin{array}{c}\% \\
\text { Vot. }\end{array}$ & Votos & Censo & $\begin{array}{c}\% \\
\text { Vot. }\end{array}$ & Votos & $\stackrel{\%}{\text { Censo }}$ & $\begin{array}{l}\% \\
\text { Vot. }\end{array}$ & 1979 & 1982 \\
\hline PNV & 349.000 & 22,3 & 36,4 & 380.983 & 25,1 & 32 & 392.428 & 25 & 39,6 & +43.428 & +11.445 \\
\hline $\mathrm{HB}$ & 186.000 & 11,9 & 29,7 & 176.117 & 11,6 & 14,8 & 141.530 & 9 & 14,3 & -44.470 & -34.587 \\
\hline$E E$ & 69.000 & 4,4 & 7,3 & 92.219 & 6,1 & 7,7 & 78.571 & 5 & 7,9 & +9.571 & -13.648 \\
\hline NaCionazistas & 604.000 & 38,6 & 63,9 & 649.319 & 42,8 & 54,5 & 612.529 & 39 & 58,4 & +8.529 & -36.790 \\
\hline PSOE & 147.000 & 9,4 & 15,6 & 349.000 & 32 & 29,4 & 264.259 & 16,8 & 26,7 & +117.259 & -84.741 \\
\hline COALICIÓN & 115.000 & 7,4 & 12,2 & 138.984 & 9,2 & 11,7 & 87.298 & 5,6 & 8,8 & -27.702 & -51.686 \\
\hline Otros & 79.000 & 5 & 8,3 & 53.970 & 3,6 & 4,6 & 25.946 & 1,6 & 2,6 & -53.054 & -28.024 \\
\hline Estatales & 341.000 & 21,8 & 36 & 542.491 & 35,7 & 45,5 & 377.503 & 24,1 & 38,1 & +36.503 & -164.988 \\
\hline IZQUIERDA & 481.000 & 30,7 & 50,9 & 647.935 & 42,7 & 54,4 & 501.101 & 32,3 & 50 & +26.101 & -140.834 \\
\hline DERECHA & 464.000 & 29,6 & 49,1 & 543.875 & 35,8 & 45,6 & 506.348 & 32,3 & 50 & +42.348 & -37.527 \\
\hline Votantes & 970.000 & 61,8 & 100 & 1.223 .199 & 80,6 & 100 & 1.013 .449 & 64,6 & 100 & +43.449 & -209.750 \\
\hline Censo & 1.567 .437 & 100 & - & 1.518 .402 & 100 & - & 1.568 .806 & 100 & $\ldots$ & +1.369 & +80.404 \\
\hline
\end{tabular}


sauri, Irún, Mondragón, Galdácano y Erandio, mientras que los pierde en los 10 restantes $(10.000$ en total, de los que 5.000 pertenecen a Bilbao y 2.000 a San Sebastián).

EI PSOE, el segundo partido de la CAV y el primeto de Navarra, gana más de 150.000 votos con respecto a 1979 pero pierde más de 90.000 con respecto a octubre, especialmente en Vizcaya (-38.000) y Guipúzcoa $(-28.000)$, aunque también en Alava y Navatra $(-7.000)$. Más concretamente, pierde los 60.000 votos en los 18 mayores municipios de la CAV, destacando los 14.000 de Vitoria y Bilbao y los casi 7.000 de San Sebas. tián, siendo Sestao el único municipio con gestión socialista desde 1979 el que se mantiene.

Hetri Batasuna sigue ocupando la tercera posición en el sistema de partidos, perdiendo 50.000 votos desde 1979 y 36.000 desde las últimas elecciones generales, siendo ésta una tendencia que se da en todas las provincias, pero especialmente en Vizcaya. $\mathrm{Si}$ a las pérdidas netas de $\mathrm{HB}$ les añadiésemos las de los partidos que habían recomendado el voto para esta coalición, el descalabro sería aún mayor, habiendo perdido una cuarta parte del electorado desde su cota más alta conseguida en las elecciones provinciales de 1979. Si observamos lo ocurrido en las poblaciones mayores de 20.000 habitantes de la $\mathrm{CAV}, \mathrm{HB}$ pierde alrededor de 20.000 votos en conjunto, no ganando electores en ninguna y consiguiendo mantenerse tan sólo en Llodio y Hernani.

La coalición de la derecha se sitúa en cuarta posición en la CAV y, aunque pierde votos con respecto a $1979(-28.000)$, pierde, significativamente, más en los últimos meses $(-52.000)$. Concretamente en este último período pierde adeptos en todos los grandes municipios $(-32.000)$ y especialmente en Bilbao $(-12.000)$ y Vitoria $(-8.000)$. En Navarra, sin embargo, de la división inicial entre UCD y UPN, apoyada por AP, pasamos a la actual entre UPN y AP-PDP-UL, perdiendo, en conjunto, unos 10.000 votos con respecto a 1979 y algo menos con respecto a 1982 .

Finalmente, Euskadiko Ezkerra, que gana unos 10.000 votos con respecto a 1979 (20.000 en Vizcaya), pierde 15.000 desde octubre (6.000 en Guipúzcoa), lo cual la convierte en la opción más estable tras el PNV. Desde octubre sólo incrementa sus efectivos en Baracaldo y Rentería, per. diendo en las 16 grandes poblaciones restantes cerca de 10.000 votos.

Si de las opciones concretas pasamos a los bloques de partidos o grandes tendencias ideológicas, tenemos las siguientes conclusiones:

El nacionalismo, la primera coordenada del sistema político vasco, en ascenso continuo desde 1977, comienza a declinar a partir desde este momento, al perder desde octubre 37.000 votos en la CAV y ottos 6.000 en 
Navarra, por efecto del descenso de la izquierda abertzale no compensado por los incrementos del PNV.

La izquierda, la segunda coordenada de la estructura electoral vasca, que se había equiparado al nacionalismo en octubre, pierde más de 160.000 votos desde entonces, a lo que contribuye tanto la izquierda moderada como la izquierda radical y abertzale.

La derecha, la tercera coordenada, se equipara prácticamente con la izquierda, por ptimeta vez, a pesar de que también pierde casi 50.000 votos desde octubre en el conjunto de la CAV y Navarra.

Las opciones estatales, la cuarła dimensión del comportamiento político vasco, las que más habían ascendido en octubre, son las que sufren un descenso mayor al perder 175.000 electores en conjunto.

Finaimente, la abstención, la quinta dimensión de nuestra estructura política, desmoviliza desde octubre a unos 250.000 electores en las cuatro provincias, si bien con una incidencia mayor en la CAV (alrededor de un $35 \%$ de abstención) que en Navarra (29\%).

Si de los datos absolutos pasamos al peso relativo que cada opción y cada bloque representa en función de los porcentajes calculados sobre el censo electoral, tal como se representa en los gráficos 1 y 2 , tenemos las siguientes conclusiones:

El nacionalismo, después de la cota máxima del $43 \%$ del electorado obtenida en 1982 en la CAV, sufre su segundo tropezón descendiendo al $39 \%$ que representa tras las elecciones provinciales de 1983. Mientras que el PNV se consolida en su techo máximo de la cuarta parte del electorado alcanzada en octubre, la izquierda abertzale pierde posiciones; así, HB baja al $9 \%$ del electorado inferior a su cota inicial de arranque en marzo de 1979 y EE se sitúa en el $5 \%$ que alcanzara en esa mistna fecha. EI PNV, por otra parte, representa el $64 \%$ del voto nacionalista, lo que le convierte claramente en hegemónico en esa coordenada.

La izquierda, después de la cota máxima del $43 \%$ del electorado de la CAV obtenida en 1982, sufre su segundo tropezón al perder 11 puntos y representar a sólo un tercio escaso $(32 \%)$ del censo. De este descenso, como hemos visto, no se libra ni la izquierda moderada, ni la radicai, ni la estatal, ni la abertzale. Con todo, el PSOE sigue representando a un $17 \%$ del electorado de la CAV y a una cuarta parte del navarro y sigue acaparando más de la mitad del voto de una izquierda muy fragmentada y difícil de reconciliat.

La derecha, que babía superado a la izquierda en 1977 y 1980 , vuelve a equipatse a ésta en torno a un tercio del electorado, a pesar de que haya perdido 3,5 puntos desde octubre. El PNV acentúa su hegemonía 
sobre este bloque al acaparar el $78 \%$ de este voto en la CAV, si bien en Navarra la situación es muy distinta con UPN controlando el $51 \%$ de este electorado conservador, mientras que el PNV sólo tepresenta un $15 \%$ del mismo. Es de resaitar, por otra parte, que en la CAV la coalición de la derecha, después de la leve recuperación que experimentó en 1980 y 1982 , llega en estas elecciones a la cota más baja, representando tan sólo a un escaso $6 \%$ del electorado.

El conjunto de las opciones estatales vuelve a retroceder en su posición relativa en la CAV, no llegando a representar ni a una cuarta parte del electorado, perdiendo 12 puntos con respecto a octubre y convirtiéndose el PSOE en hegemónico en este bloque al captar el $70 \%$ de sus votos.

Sin duda alguna, el elemento de distorsión más importante es la abstención, que, si en octubre se había reducido al $19 \%$ en la CAV y al $18,5 \%$ en Navarta, ahora vuelve a incrementarse al $35 \%$ y al $29 \%$, respectivamente.

No hay nadie que, de uno u otto modo, no se haya visto afectado por esta desmovilización electoral, pero lo significativo es que, si desde hace cuatro años venía afectando masivamente al electorado no identificado y de aluvión de las opciones mayoritarias estatales, ahora ha llegado a tocar también a los sectores nacionalistas, especialmente los más radicales, que representaban las pautas típicas del electorado más identificado, fiel y movilizable tras los símbolos y las reivindicaciones de la identidad colectiva y la lucha antirrepresiva.

\section{a) DIFÍCIL GOBERNABILIDAD EN LAS INSTITUCIONES FORALES DE LOS TERRITORIOS HISTÓ́RICOS}

Ahora vamos a dejar a un lado los votos y tomaremos en cuenta las concejalías y los representantes forales conseguidos por cada opción, que nos darán idea del reparto del poder institucional local y foral de la CAV y Navarra tras las elecciones del 8 de mayo de 1983 y en relación con las de abril de 1979.

La conclusión genérica es que se ha complicado la gobernabilidad en las instituciones forales, a pesar de que HB haya renunciado a ocupar sus escaños, y les sucede lo mismo a los ayuntamientos más importantes de ambas comunidades, situándose ante el galimatías de coaliciones, pactos, mociones y tomas de posición, casi todos imposibles y conflictivos, que se barajan desde el comienzo de la legislatura.

Antes de todo, tenemos que recordar que, si bien el sistema electoral para las elecciones municipales es común a todos los municipios, el de las 
elecciones forales se tige por normas autonómicas específicas; así, mientras que para el Parlamento Foral Navarro la provincia funciona como distrito único (en 1979 las merindades constituían circunscripciones electorales), para las Juntas Generales de Alava, Guipúzcoa y Vizcaya éstas funcionan divididas en 7 distritos con magnitudes ponderadas en favor de los de me. nor peso demogtáfico y mayor concentración relativa del voto nacionalista.

$\mathrm{Ya}_{\mathrm{a}}$ en su momento he criticado amplia y razonadamente la normativa electoral impuesta por el PNV para su exclusivo provecho, ahora se confirma aquella crítica, puesto que, si al PNV le cuestan sus 73 escaños en la CAV algo más de 5.000 votos por término medio, al PSE sus 39 , a HB sus 21 y a la Coalición sus 13 les cuestan alrededor de los 7.000 , mientras que a EE sus 6 escaños le cuestan algo más de 13.000, impidiendo, por lo demás, el acceso a las instituciones forales a otros partidos menores (PCE y CDS).

Por lo tanto, el índice de desigualdad por escaño oscila de 3 (EE) a 0,85 (PNV) en Álava, de 2,1 (Coalición) a 0,79 (PNV) en Guipúzcoa y de 1,75 (EE y Coalición) a 0,75 (PNV) en Vizcaya; teniendo en cuenta que todos los demás están por encima del índice 1, el voto del PNV es pon derado en todos los casos en detrimento de los demás.

Esta distorsión, sin embargo, es mucho menor en Navarra, donde con una ley más justa, el PNV, el último del Parlamento Foral, padece un índice de desigualdad de 1,3 frente al 0,9 de todos los demás, costándole cada uno de sus escaños aigo más de 1.000 votos por encima del coste igualitario de los restantes partidos.

Una vez aclarado esto, vemos que el sistema de partidos parlamentarios provinciales en la CAV es muy similar: los mismos cinco partidos definen un pluralismo de base, fuertemente polatizado, con el PNV como partido hegemónico (con mayoría absoluta) en las JJ. GG. de Vizcaya y con el PNV como partido dominante en medio de una mayor fragmentación parlamentaria en Álava y Guipúzcoa, en donde la ausencia institucional de HB facilita la hegernonía del PNV en la última y el gobierno provincial de dicho partido en la otra.

En cualquier caso, las mayorías que se podtían formar en las instituciones forales de la CAV sólo podrían ser nacionalistas o de derecha, en cuyos bloques el PNV es el partido hegemónico. Con una normativa electoral más igualitaria la fragmentación habría sido mayor, el PNV no tendría hegemonía en ningún caso y sólo la ausencia de HB facilitaría la gobernabilidad, así como su presencia posibilitaría mayorías de izquierda, impensables, por otra patte, dado el deterioro de las relaciones políticas entre abertzales y socialistas.

En Navarra, por el contrario, la fragmentación es mucho mayor y ni la 
ausencia de $\mathrm{HB}$ facilita las cosas, tanto al partido mayoritario (PSOE) como a la muy probable coatición de derecha (UPN-AP), dependiendo cualquier combinación de la posición del PNV.

Así pues, institucionalmente y supuesta la ausencia de HB, el PNV asegura su hegemonía en Guipúzcoa y Vizcaya al controlar en solitatio las respectivas diputaciones forales y las JJ. GG. que las soportan, pero sigue faltándole un voto para gobernar holgadamente en Alava y adquiere un papel de árbitro en el gobiemo de Navarra, lo cual puede suponer que, intercambiando el voto o la abstención con la derecha, haya conseguido, además de la Diputación alavesa, las alcaldías de las tres capitales de la CAV.

b) EL PNV CONTROLA EI PODER DE LA MAYORÝa

DE LOS MUNICLPIOS MENORES, PERO EN LOS GRANDES

EL PNV y EL PSOE SE ENCUENTRAN CON UNA DIFícIL GOBERNABILIDAD

Sólo nos queda estudiar la evolución del poder municipal. Para ello, el primer dato que tendremos en cuenta son las candidaturas presentadas por los distintos partidos, lo cual nos puede dar idea de la implantación territorial y del liderazgo local de los mismos.

El PNV presenta candidaturas en 206 de los 500 municipios de la CAV y Navarra, lo que supone una cobertura de más del $40 \%$ de la estructura local y más de las tres cuartas partes de la población total. Esta cobertura es prácticamente general en la CAV, mientras que no llega al $10 \%$ de los municipios de Navarra, locilizándose en la metindad de Pamplona, en la propia capital, la zona norte y la Barranca, que suponen, aproximadamente, la mitad de la población navarta.

El PSOE presenta candidaturas en un tercio de los municipios de ambas comunidades, to que representa la mitad de los municipios alaveses, un $40 \%$ de los vizcaínos, un $46 \%$ de los guipuzcoanos y una cuarta parte de los navarros, localizándose siempre en los de mayor tamaño y agrupando a las tres cuartas partes de la población.

HB presenta candidaturas en un tercio de los municipios, siendo la cobertura del $10 \%$ en Navarra, dei $14 \%$ en Alava, del $63 \%$ en Guipúzcoa y del $75 \%$ en Vizcaya, distribuyéndose con una gran heterogeneidad territorial y de volumen, ya que, aunque se presenta en todas las grandes poblaciones, lo hace también en buen número de las pequeñas, siendo, por otra parte, la opción que en mayor número de candidaturas independientes o unitarias participa. 
La Coalición y UPN presentan un centenar de candidaturas, to que supone una quinta parte del total, distribuyéndose en un $4 \%$ en Guipúzcoa, un $19 \%$ en Vizcaya, la mitad de los municipios alaveses y un $20 \%$ de los navarros, si bien, en esta última provincia, controlan buen número de candidaturas de independientes, siendo, igualmente, muy amplia la cobertura demográfica de sus listas.

EE presenta algo más de un centenar de candidaturas propias, una quinta parte del total de municipios de ambas comunidades, con una cobertura territorial del $2 \%$ de los mismos en Navarra, el $14 \%$ en Álava, el $46 \%$ en Vizcaya y el $52 \%$ en Guipúzcoa, que representan más de los dos tercios de la población, al localizarse en los municipios mayores.

Al lado de estas candidaturas hay que añadir las 560 presentadas con denominaciones $y$ formaciones muy diversas, todas ellas catalogadas como «independientes» y que tienen una gran presencia en Navarra, donde, por otra parte, hay un gran númeto de municipios en los que no se presenta ninguna candidatura o lo hace una única candidatura independiente. Por otra parte, por primera vez aparecen en algunos municipios candidaturas alternativas (verdes o ecologistas) antes aglutinadas por la izquierda abertzale, pero ahora desgajadas de ésta.

Aunque esta distribución ya nos da una idea de la implantación de los distintos partidos, la evolución del poder en cada provincia es la siguiente:

1. ${ }^{\circ}$ En Álava la derecha controla la práctica totalidad de los ayuntamientos con una hegemonía clara del PNV, mayoritario en 41 de los 51 municipios y con mayoría absoluta en 31 . Es cierto que, a pesar de todo, la izquierda, y más concretamente el PSOE, han avanzado en buena parte de las localidades. El PNV pasa de 143 a 200 concejales, el PSOE de 29 a 53 , Ia detecha se queda con 63 y el resto obtiene una treintena. Sólo Vitoria y Llodio se escapan al control holgado de la derecha.

2. En GurpúzCOA, si tenemos en cuenta la anteriot composición de las candidaturas independientes y su disminución de 232 a 102, lo que indica una clarificación política, se produce un estancamiento, si no retroceso, del nacionalismo, especialmente en los municipios mayotes, a pesar de que el PNV pasa de 360 a 392 concejales, HB de 127 a 163 y EE de 59 a 65 . Se produce un avance claro de la izquierda de la mano del PSOE, con mayoría en 6 de los 7 municipios mayores de 20.000 habitantes, en 6 de los 13 mayores de 10.000 y en otros 11 menores, lo que supone más del $60 \%$ de la población. Es interesante apuntar que, a pesar de los retrocesos relativos que sufren en importantes municipios $\mathrm{HB}$ y $\mathrm{EE}$, estas dos opciones de la izquierda abertzale consiguen mayoría en Hernani, Tolosa 
y otros 7 municipios menores de 10.000 habitantes, mientras que el PSOE, que pasa de 80 a 127 concejales, la consigue en los municipios más industriales. Con todo, el PNV, casi único representante de la derecha en el poder local, consigue el control de más de la mitad de los municipios guipuzcoanos y, sobre todo, en sitios tan significativos como San Sebastián, Eibar y Pasajes.

3. El avance del PSOE, que pasa de 89 a 171 concejales, y de la izquierda en su conjunto, es quizá más espectacular en VizCAYa. La izquierda es mayoritaria en 7 de los 10 municipios mayores de 20.000 habitantes y en 3 de los 7 mayores de 10.000, además de en Derio, lo que supone casi el $70 \%$ de la población vizcaína. Con todo, el PNV, que retrocede ligeramente en los muricipios más importantes, pasa de 545 a 617 concejales y obtiene la mayoría absoluta en 69 de los 101 municipios vizcaínos, a las que hay que añadit otros 8 en los que es la lista más votada y entre los que se encuentran sitios tan significativos como Bilbao, Guecho y Bermeo. A HB, si le descontamos sus independientes pierde concejales, aunque pase de 131 a 134, especialmente en las zonas industriales; EE duplica sus concejales al pasar de 24 a 48 en las grandes poblaciones y adquiere un papel más importante en la formación de las mayorías en éstas; la derecha, con 26 concejales y una presencia muy localizada en el Gran Bilbao, se estanca, aunque es decisiva para la gobernabilidad de Bilbao, por ejemplo; el PCE y los demás partidos menores tetroceden claramente.

4. Navarra presenta un poder local más heterogéneo, controlado en su parte más significativa por el PSOE, cuyo avance es aquí más nítido, consiguiendo 232 concejales, seguido de UPN con 85 , el PNV con 61, $\mathrm{HB}$ con 59, AP con 56 y 10 más para el testo de los partidos menores, además de la proliferación de candidaturas independientes (un $66 \%$ del total de las presentadas). EI PSOE consigue la mayoría en gran número de municipios $\mathrm{y}$, consiguientemente, las alcaldías más importantes de Na* varta, localizándose, sobre todo, en la Ribera y en la merindad de Pamplona. UPN tiene su poder local distribuido en toda Navarra, AP-PDP-UL lo concentran en la merindad de Tudela y el PNV y HB en la de Pamplona, consiguiendo mayorías nacionalistas en una veintena de municipios del notte.

5. En las cuatro capitales el PNV y el PSOE gobernarán enfrentados y sobre un polvorín, resumiendo la situación de los grandes municipios industriales y de la mayor parte de la población de ambas cotounidades. 
El incremento de la fragmentación municipal y la precatia formación de mayorías dificuitará la gobernabilidad de nuestras capitales, en las que el PNV y el PSOE comparten la mayoría. El PNV, que pierde concejales en Bilbao y Pamplona y los gana en Vitoria y San Sebastián, mantiene la mayoría relativa en las tres capitales de la $\mathrm{CAV}$ con bloques mayoritarios alternativos: nacionalistas en las tres y de derecha en Vitoria y Bilbao frente a una posible mayotía de izquierda en San Sebastián. El PSOE, por el contrario, consigue la mayoría en Pamplona únicamente con el apoyo del bloque de izquierda también mayoritario. En definitiva, el PNV tiene un saldo negativo de 1 concejal en las cuatro capitales, $\mathrm{HB}$ y la derecha pierden un tercio de sus concejales, el PSOE duplica los suyos y EE tiene un saldo positivo de uno. Sin duda alguna, el mayor descalabro socialista se ha producido en Vitoria, donde, con los resultados del 28 de octubre en la mano, el PSOE confiaba en conseguir la mayoría. La imposible formación de mayorías de gobierno en los grandes municipios a la hora de elegir los alcaldes $y$ la política de confrontación de $H B$ van concretando por el mo mento la citada tesis de la difícil gobernabilidad local, de la que los sucesos de Itún, Rentería y ottos son un ejemplo.

Concluyendo, los cambios en la estructura del poder local tienen las siguientes características:

- El PNV refuerza su hegemonía y su poder en la gran mayoría de los municipios de la CAV y, aunque gana concejales, pierde poder en las principales poblaciones industriales mayores de 20.000 habitantes, to cual es más significativo que el simple incremento de electos.

- El PSOE duplica su númeto de concejales consiguiendo mayorías atriesgadas en los principales centros urbanos de Guipúzcoa y Vizcaya, avanzando en todas las provincias y convirtiéndose en la primera fuerza política en gran parte de Navarra.

- La derecha, hegemonizada por el PNV en la CAV, controla casi toda Alava, la mayor parte de los municipios medianos y pequeños de Guipúzcoa y Vizcaya y consigue mayorfas importantes en las tres capitales y otzas poblaciones significativas como Guecho; por otra parte, este mismo bloque de derecha, hegemonizado por UPN, controla una importante porción de los municipios navarros.

- La izquierda, hegemonizada por el PSOE, avanza en todas las provincias, logrando mayoría en Pamplona y San Sebastián y controlando el poder, desde la alcaldía o desde la oposición, en los más importantes municipios de ambas comunidades. Con todo, las difíciles relaciones políticas 
entre el PSOE y HB difcultan enormemente las posibilidades de actuación conjunta de este bloque.

- El racionalismo, hegemonizado por el PNV, consigue la mayoría absoluta en las tres capitales y gran parte de los municipios de la CAV, así como un puñado de localidades del norte de Navarra, si bien, en conjunto, pierde poder ante el ascenso del PSOE y del bloque de izquierda que éste hegemoniza en los ayuntamientos mayores. No obstante, las posibilidades de actuación conjunta de este bloque son mucho mayores, especialmente en el terreno simbólico y de las cuestiones autonómicas y culturales que afecten a la identidad colectiva vasca, como ya está empezando a suceder a propósito de las mociones sobre el plan ZEN y las banderas.

Hecho este apunte descriptivo de la estructura electoral vasca, queda ahora la parte más importante del análisis, es decir, la explicación de la dinámica sociológica que hay detrás del comportamiento político de nuestra población y las implicaciones que esto ha de suponer para la reconducción de las relaciones y del discurso políticos en las comunidades autónoma $y$ foral.

\section{LAS DIMENSIONES DEL DISTANCIAMIENTO IDEOLOGICO DEL ELECTORADO VASCO}

Utilizando las mismas escalas de autoubicación nacionalista/no nacio nalista e izquierda/derecha obteníamos en el verano de 1981 las siguientes posiciones medias de los electorados de los distintos partidos tras las elecciones autonómicas de 1980 sobre una muestra de 1.800 entrevistados de la CAVP (gráfico 4, página siguiente).

Como se puede ver, el tecorrido promedio en ambas escalas es 4,2 y 3,9 respectivamente, que resulta de restar las puntuaciones de las posiciones extremas (HB y AP), que suponen una fractura importante en el espectro político vasco.

Por otra parte, mientras que las posiciones colaterales se refuerzan en ambas escalas (AP: 3,6 y 3,5; UCD: 5 y 4,9 ; EE: 7,5 y 7,3 , y HB: 7,8 y 7,4 ), las posiciones centrales suften desplazamientos significativos; así, el PNV pasa de una posición moderada $(5,9)$ en la escala ideológica a otra más radical $(6,9)$ en la nacionalista, mientras que el PSOE pasa de 6,7 a 5,4 , el PCE de 7,3 a 5,8 y el bloque abstencionista de 6,4 a 5,5 .

Es cietto que en un anâlisis cualitativo no son equiparables ambas dimensiones politicas, en la medida en que la primera apela, predominan- 
teraente, a componentes racionales e ideológicos y la segunda lo hace a teferenciales simbólicos, mucho más escurridizos para el cálculo y la previsión.

\section{GŔ́rico 4}

Promedios en la escala de autoubicación ideológica de los principales electorados en 1980

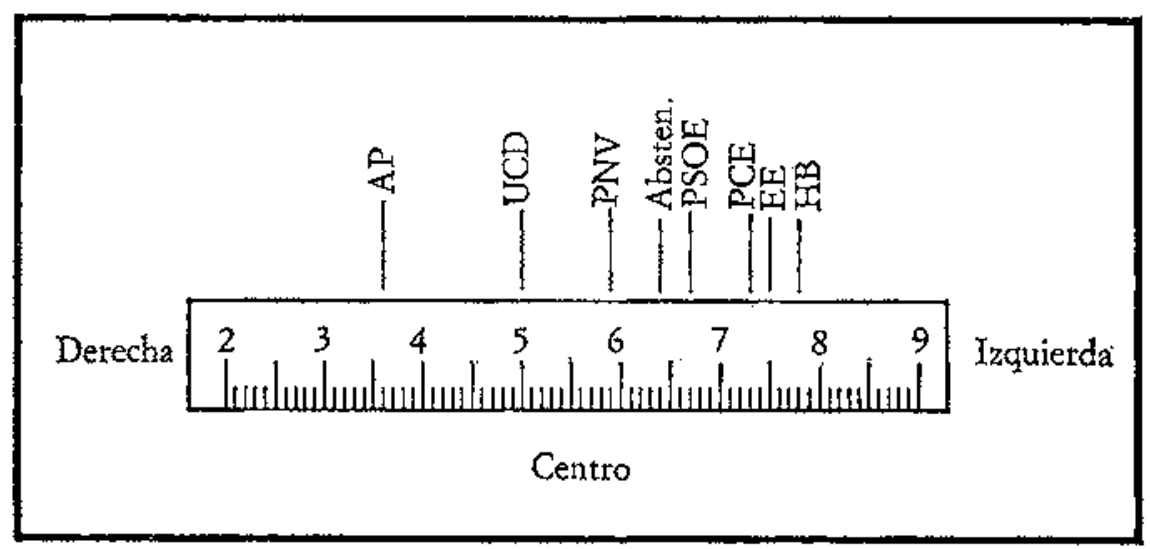

GráfICO 5

Promedios en la escala de autoubicación nacionalista de los principales electorados en 1980

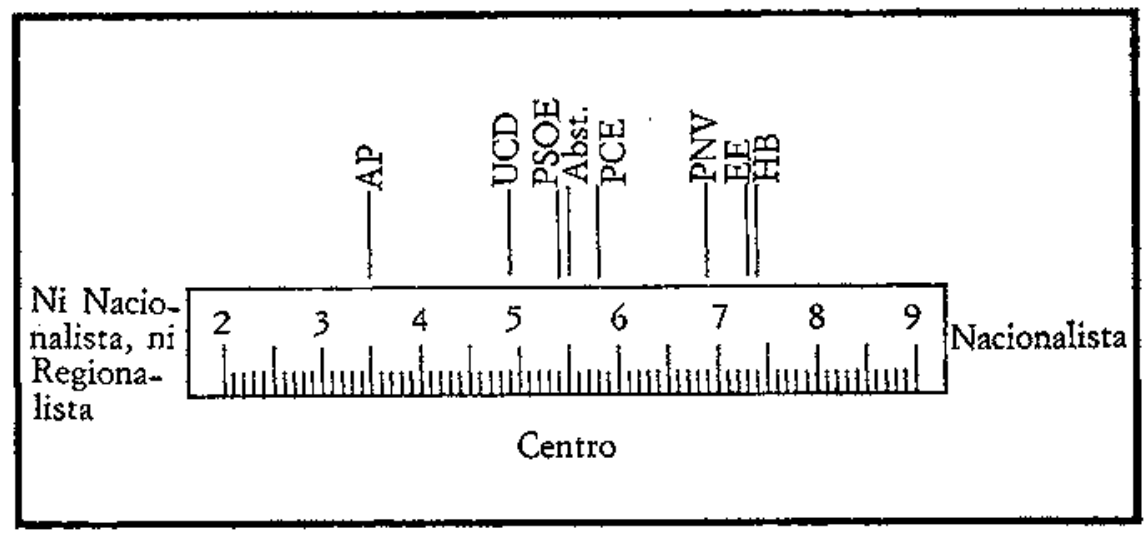


Por otra parte, mientras que esta segunda define una fidelidad mucho mayor y se inscribe en un área de identificación, la otra está mucho menos cristalizada en nuestro electorado, produce una mayor movilidad electoral y se inscribe en un área de competición cuyo intervalo puede venir indicado por la oscilación de las puntuaciones medias del grupo abstencionista.

Obviamente, detrás de estas dimensiones simplificadas existen una multiplicidad de indicadores políticos, motivacionales y simbólicos que explican la polarización existente en nuestro sistema de partiỏos, así como la crisis de legitimación en la que se inscribe.

Concretamente vamos a fijarnos en cinco indicadores, a saber: la identificación con lo español o lo vasco, la posición ante el euskera, la organización del Estado, la posición ante las instituciones y la actitud ante ETA.

\section{a) LA IDENTIIFICACIÓN CON LO ESPAÑOL}

Es sumamente interesante comparar el grado de identificación con «lo español» y las tespectivas autoubicaciones de los entrevistados en las escalas derecha/izquierda y de nacionalismo. Véase la tabla 5.

Si relacionamos las identidades extremas y excluyentes con la autoubicación en ambas escalas, observaremos que, aun siendo las distintas identidades de una gran heterogeneidad ideológica, los porcentajes máximos describen una diagonal perfecta, que va desde la tnáxima definición española $(27 \%$ y $37 \%)$ en el extremo de ambas escalas en que se ubican las posiciones antinacionalistas y de derecha, hasta la máxima definición vasca $(69 \%$ y $51 \%$ ) en el otro extremo de ambas escalas en que se ubican las posiciones del nacionalismo y la izquierda radicales, pasando por el máximo peso de los binomios español/vasco (54\% y $41 \%$ ) y vasco/español ( $48 \%$ y $37 \%$ ) en las posiciones de centro moderado o de centro radical, respectivamente, de ambas escalas.

Tratando de averiguar la composición ideológica exacta de las distintas definiciones de identidad, obtenemos la tabla 6 .

Como se puede observar, Ia identificación española excluyente es rotundamente $(63 \%)$ antinacionalista y mayoritariamente de centro $(61 \%)$, tanto de centro-derecha como de centro-izquierda. El binomio identificador español/vasco se reparte por igual entre el antinacionalismo moderado $(28 \%)$, el antinacionalismo radical $(25 \%)$ y el nacionalismo modetado $(26 \%)$, definiendo el tegionalismo de centro (64\%), sobre todo de centro-izquierda (45\%). Por su parte, el binomio vasco/español es predo. minantemente nacionalista $(64 \%)$, aunque mayoritariamente moderado $(48 \%)$ y de centro izquierda $(48 \%)$. 
«Papers»: Revista de Sociologia

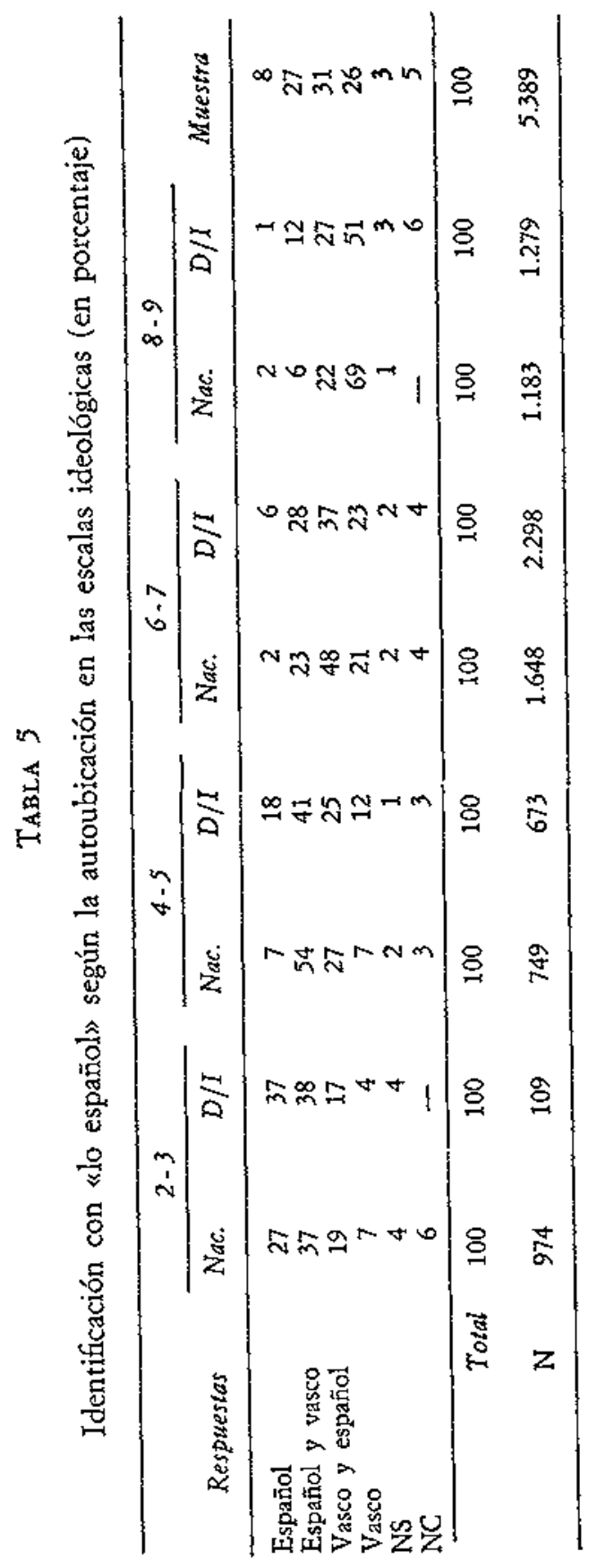


La estructura política vasca en 1983

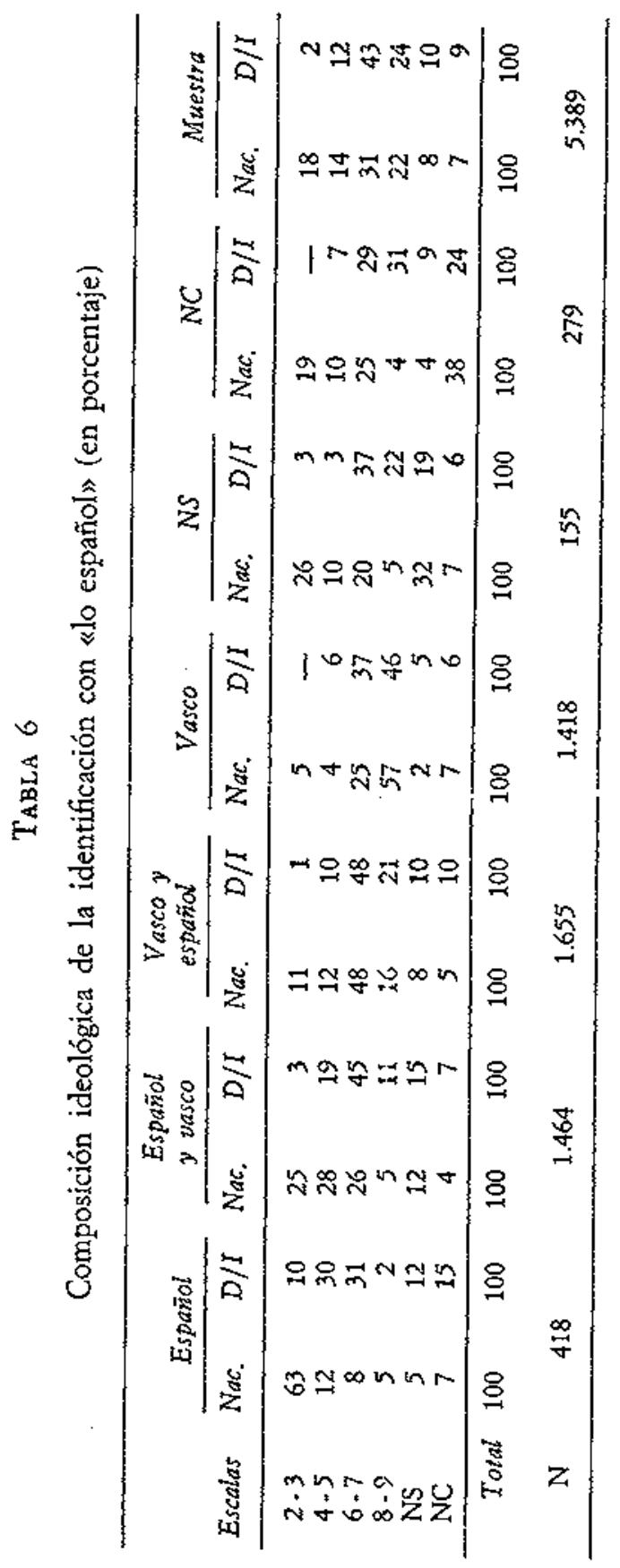


Finalmente, la definición vasca excluyente es totundamente nacionalista $(57 \%)$, desde las posturas más radicales ( $34 \%$ ) a las más modera. das $(25 \%)$, e ideológicamente más orientada a la izquierda que ninguna otra posición. Las posiciones extremas de esta categoría suponen un $9 \%$ de nacionalismo radical respecto del total y un $5 \%$ de extrema izquierda.

Al igual que hace un año podemos decir que, en conjunto, el factor nacionalista amortigua la radicalización ideológica en el centro de un continuum, a pesar de que en la extrema izquierda confluya una parte no desdeñable de los entrevistados, que oscila entre el $12 \%$ (en los puntos 8 y 9 de la escala derecha/izquierda) y el $15 \%$ (en las mismas puntua. ciones de la escala de nacionalismo), que se deciaran vascos excluyentes.

No obstante, el factor positivo es la gran moderación ideológica de la mayor parte de la población y la ausencia de una bipolarización fuerte antinacionalista ( $4 \%$ del total) de extrema derecha (no llega al $1 \%$ ) y español excluyente ( $8 \%$ ).

\section{b) LA POSICIÓN ANTE EL EUSKERA}

El euskera se nos muestra, además de como un indicador de identidad colectiva, como un indicador de integración social claro y con una fuerte penetración en el tejido social. Puede ser de sumo interés estudiar el com. portamiento de las distintas familias ideológicas, pata lo cual tomamos en consideración la distribución de las clientelas electorales de 1980.

La filiación ideológica discrimina significativamente la posición y la actitud ante el euskera de nuestzos entrevistados. Así:

- AP, y especialmente UCD, destacan por su desinterés con respecto al euskera ( $48 \%$ y $63 \%$, respectivamente) $-61 \%$ conjuntamen. te--; sólo un tercio escaso lo ve con buenos ojos, son contados los que lo están aprendiendo $\mathrm{y}$, aunque no son muchos, en AP los que ya saben eusketa $(20 \%)$ superan a los que to hacen en UCD (5\%), lo cual denota un electorado más enraizado en el país por parte de los primeros - en conjunto, los dos electorados alcanzan un $7 \%$,

- En el electorado del PSOE el $85 \%$ se divide por igual entre los que ven con buenos ojos el euskera y los que no les interesa. Por lo tanto, es un público relativamente más favorable al euskera que el de centroderecha. A su vez, son más los que ya lo están aprendiendo $(6 \%)$ y parecido el porcentaje $(9 \%)$ de los que ya lo 


\section{TABLA 7}

Posición ante el Euskera según la clientela electoral en 1980 (en porcentaje)

\begin{tabular}{|c|c|c|c|c|c|c|c|c|c|c|c|c|c|c|}
\hline \multirow{2}{*}{\multicolumn{2}{|c|}{ Euskera }} & \multirow[b]{2}{*}{$A P$} & \multirow[b]{2}{*}{$E E$} & \multirow[b]{2}{*}{$H B$} & \multirow[b]{2}{*}{ PCE } & \multirow[b]{2}{*}{ PNV } & \multirow[b]{2}{*}{$P S E$} & \multirow[b]{2}{*}{$U C D$} & \multirow{2}{*}{$\begin{array}{l}\text { Otros } \\
\text { izq. }\end{array}$} & \multicolumn{5}{|c|}{ Abstencion * } \\
\hline & & & & & & & & & & $\overline{1}$ & 2 & 3 & 4 & 5 \\
\hline No saben, no interesa & & 48 & 6 & 7 & 26 & 14 & 42 & 63 & 10 & 16 & 25 & 36 & 21 & 23 \\
\hline No saben, interesa & & 32 & 38 & 38 & 43 & 35 & 43 & 30 & 43 & 36 & 42 & 32 & 39 & 37 \\
\hline Aprenden & & - & 15 & 18 & 3 & 7 & 6 & 2 & 24 & 20 & 9 & 5 & 14 & 10 \\
\hline \multicolumn{15}{|l|}{ Entienden, hablan } \\
\hline leen y escriben & & 20 & 40 & 36 & 28 & 43 & 9 & 5 & 23 & 28 & 24 & 27 & 24 & 28 \\
\hline NS & & - & - & - & - & 一 & - & - & $\rightarrow$ & - & - & - & - & - \\
\hline \multirow[t]{3}{*}{$\mathrm{NC}$} & & - & 1 & 1 & - & 1 & - & - & $\rightarrow$ & - & - & - & 2 & 2 \\
\hline & Total & 100 & 100 & 100 & 100 & 100 & 100 & 100 & 100 & 100 & 100 & 100 & 100 & 100 \\
\hline & $\mathrm{N}$ & 31 & 367 & 519 & 108 & 1.106 & 501 & 158 & 113 & 347 & 249 & 509 & 399 & $5.389^{\circ}$ \\
\hline
\end{tabular}

* 1: No edad; 2: No posibilidad; 3: Cansancio; 4: Razones polfticas; 5: Muestra. 
saben, que se quedan, por otra parte, muy por debajo del $25 \%$ del conjunto de la muestra. Es éste un electorado de transicion.

- Sin embargo, en el resto de las opciones de izquierda no nacionalista se reduce mucho más el índice de desinterés (18\% en conjunto), se mantiene el mismo nivel de interés (43\%) que entre el PSOE, aumenta claramente la proporción de los que ya lo están aprendiendo (14\%), especialmente entre la izquierda radical, y alcanza el porcentaje muestral la de los que ya lo saben $(26 \%)$. Se trata, por tanto, de un sector de población más integrado y cercano a la posición del nacionalismo en este tema.

- La teducción del desinterés ( $16 \%$ ) continúa en el contingente de entrevistados que no han votado en 1980 por no tener la edad, aumen. tando ligeramente el de los que ya lo saben ( $28 \%$ ) y dando el porcentaje máximo de los que lo están aprendiendo (20\%).

- Los grupos nacionalistas destacan pot la aita proporción (en torno al $40 \%$ ) de los que ya saben euskera, la de los que lo están apren. diendo ( $12 \%$ en conjunto) y, consecuentemente, la mínima (11\%) de los que muestran desinterés por el tema. Sin embargo, es de destacar que las diferencias internas explican las contradicciones y polémicas sociales que existen en este momento respecto a la politica de reuskaldunización; así, mientras que en el PNV destaca la mayor proporción de euskaldunes (43\%) sobre HB (36\%), entre la izquierda abertzale -al igual que entre la izquierda extraparlamentaria no nacionalista $(24 \%)$ y los jóvenes que no han votado nunca $(20 \%)$ - destacan los que lo están aprendiendo (HB: $18 \%$ y EE: $15 \%$ ) sobre el PNV (7\%) y el menor número de desinteresados (7\% y $6 \%$ de $\mathrm{HB}$ y EE frente al $14 \%$ del PNV).

- Finalmente, el contingente de la abstención se caractexiza por tener una distribución intermedia entre el nacionalismo y la izquierda. Tiene un contingente de población euskaldún (en torno al $25 \%$ ) menor que el nacionalismo pero mayor que las grandes opciones nacionales (UCD y PSOE), la proporción de los que aprenden euskera $(9 \%)$ se sitúa a medio camino (siendo mayor - $14 \%$ entre los que se abstienen por razones políticas y menor - $5 \%$ los que lo hacen por cansancio) y el contingente de desinteresados se sitúa, igualmente, a medio camino ( $28 \%$ ), siendo mayo: entre los cansados $(36 \%)$, que entre los más politizados $(21 \%)$.

El euskera es claramente un factor de diferenciación de los grupos sociales, especialmente desde el punto de vista ideológico, y también de integración de las distintas capas de nuestra pobiación. 


\section{c) LA ORGANIZACIÓN TERRTTORIAL DEL EsTADO}

La mayor o menor presencia del Estado en el tejido social, su mejor o peor imagen, tienen mucho que ver con la legitimación sociológica que haya logrado el modelo de integración política seguido.

En todo caso, aparte de una mejor redefinición de la presencia del Estado y de la línea de acción de los partidos en nuestra sociedad, donde la integración política del Estado se juega el todo por el todo, es precisamente en el éxito de la empresa de su reorganización territotial donde, junto con la mejora de las relaciones políticas y la democratización general de los aparatos de la sociedad en su conjunto, supone, desde un punto de vista sociológico, si no una creación ex novo, sí una refundación en unas nuevas coordenadas políticas, cuya eficacia y legitimación sociológicas tienen mucho que ver con que lo positivo de las experiencias comunes preexistentes prime sobre la lectura negativa de esta trayectoria histórica vivida conjuntamente, muchas veces de forma traumatizante, por importantes sectores de nuestra población. Por esta razón, es interesante observar la distribución electoral de las distintas opciones.

La fómula unitaria tiene sus mejores valedores entre los electores de AP (61\%) y UCD (34\%), así como una pequeña parte de la abstención no política (12\%). El rechazo es absoluto entre los electores de EE y HB y menor en los del PNV (2\%) y PCE (1\%). Los apoyos fundamentales al Estado de las autonomías provienen del PNV (52\%), del PSOE ( $51 \%)$ y del PCE (48\%), mientras que el entusiasmo es significa. tivamente menor entre los electores de $\mathrm{HB}$ (16\%), la izquierda extraparlamentaria $(17 \%)$, los jóvenes que no han votado $(21 \%)$, los abstencionistas por tazones políticas $(25 \%)$, los electores de AP (26\%) y los de UCD $(31 \%)$.

La fómula federal, por su parte, obtiene los apoyos más significativos entre la izquietda extraparlamentaria (45\%), EE (36\%), los abstencionistas políticos (31\%) y el PCE (29\%), mientras que no obtiene ningún adepto en el electorado de AP y son pocos los que se adhieren a esta opción entre los de $\mathrm{HB}$ (11\%) y UCD (11\%).

$\mathrm{El}$ independentismo tiene su valor principal en el electorado de HB (61\%) y, en menor medida, en los de la izquierda extraparlamentatia $(31 \%)$ y EE $(24 \%)$. Por el contrario, el techazo es absoluto entre los electores de AP y UCD y menor entre los del PSOE (4\%) y el PCE (12\%).

Así pues, el electotado de AP, que es integracionista en su $87 \%$, no definiéndose el $13 \%$ restante, se catacteriza por ser mayoritariamente centralista. 
«Papers»: Revista de Sociologia

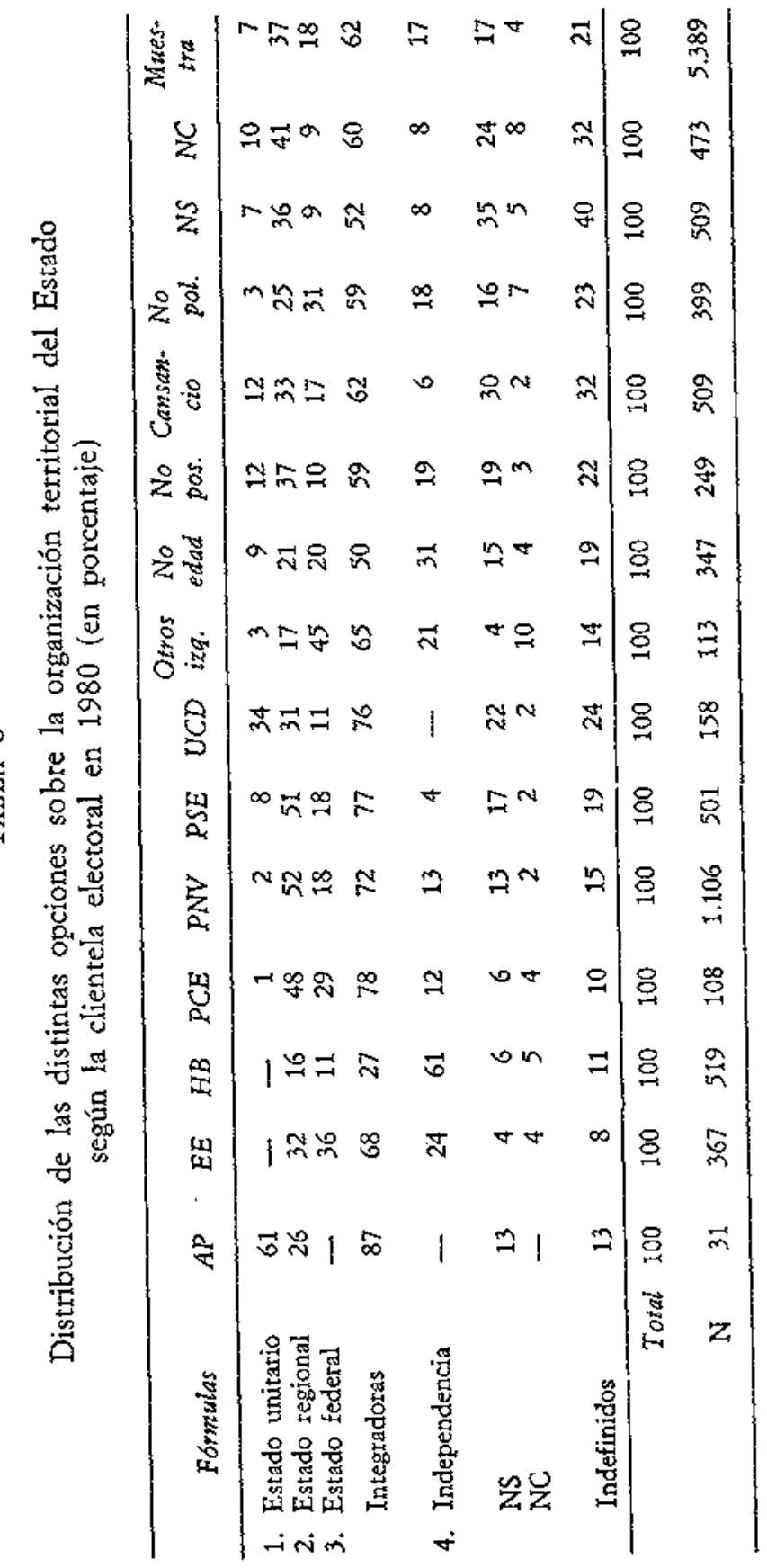


El electorado de $\mathrm{EE}$, que es mayoritariamente integracionista $(68 \%)$, se caracteriza por un relativo mayor apoyo a las opciones federal e independentista, si bien, mientras aquélla ha incrementado sus adeptos en un $15 \%$ en el último año, ésta se ha reducido a la mitad, pasando del $48 \%$ al $24 \%$ actual.

El electorado de $\mathrm{HB}$ se caracteriza por ser abrumadoramente (61\%) independentista y por persistir en esa actitud y proporción desde hace un año.

El electorado comunista, además de ser mayoritariamente integtacionista $(78 \%)$, se caracteriza por su mayor apoyo a las opciones tegional y federa!.

EI electorado nacionalista del PNV, que en sus dos terceras partes es integracionista, es ahora mayoritariamente regionalista (52\%), cuando hace un año la opción regional era mantenida por el $44 \%$, habiéndose reducido su independentismo, situado por debajo dei promedio actual ( $13 \%$ ).

El electorado socialista, ligeramente más integracionista ( $77 \%$ ) que el nacionalista, es tan regionalista y federalista como éste, aunque más centralista, menos independentista y más indefinido.

$\mathrm{El}$ electorado centrista, mucho más indefinido (24\%), aunque un tanto integracionista $(76 \%)$, es, parađójicamente, más centralista $(34 \%)$ que regionalista $(31 \%)$, habiéndose incrementado los partidarios del centralismo en un $12 \%$ en el último año.

Finalmente, la izquietda extraparlamentaria, también integracionista en un $65 \%$, se caracteriza por su federalismo $(45 \%)$ y su independentismo (21\%).

Así pues, las opciones integradoras parecen avanzar de forma notable en conjunto y en los grupos sociales anteriormente más críticos, especialmente entre los electorados del PNV y EE. Sin embargo, frente a esta dinámica centrípeta del nacionalismo moderado, el nacionalismo radical de $\mathrm{HB}$ se mantiene firme en su independentismo y, lo que es más grave, se produce una dinámica centrífuga bacia el centralismo por parte de los electorados de AP y UCD.

\section{d) LA PLAUSIBILIDAD DE LAS INSTITUCIONES}

Una fuente importante de distanciamiento cs la posición ante el edificio institucional. Veamos el comportamiento de las distintas clientelas. 


\section{TABla 9}

Juicio de las instituciones según la opción electoral en 1980 * (en potcentajes)

\begin{tabular}{|c|c|c|c|c|c|c|c|c|c|c|c|c|c|c|c|c|c|c|c|c|c|c|c|c|c|c|}
\hline Instit & $+{ }^{A P}$ & & & & $\begin{array}{r}H B \\
+\quad-\end{array}$ & & $\begin{array}{r}P C \\
+\end{array}$ & 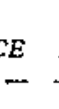 & $\begin{array}{l}P N V \\
+\quad-\end{array}$ & & & & & $\begin{array}{l}\text { Otro } \\
\text { izq. } \\
+\end{array}$ & & $\begin{array}{r}\text { No } \\
\text { edo } \\
+\quad-\end{array}$ & iad & No & & $\begin{array}{l}\text { No } \\
\text { pos. } \\
-\end{array}$ & $\begin{array}{l}\text { Canso } \\
+\quad-\end{array}$ & & $\begin{array}{r}N S \\
+\quad-\end{array}$ & $\begin{array}{r}N C \\
+\quad-\end{array}$ & & estra \\
\hline 1. E1 & 81 & 16 & 45 & 442 & $20 ?$ & 73 & 503 & 327 & $72 \quad 18$ & 76 & 11 & 89 & 3 & 297 & 714 & 433 & 364 & 463 & 62 & 19 & 612 & 245 & $56 \quad 19$ & $64 \quad 13$ & 57 & 28 \\
\hline 2. & 87 & 10 & 35 & 92 & 45 & 91 & 107 & 791 & 1960 & 30 & 53 & 59 & 18 & 49 & 951 & 117 & 72 & 8 & 20 & 61 & 314 & 482 & $23 \quad 45$ & $25 \quad 45$ & $5 \quad 19$ & 62 \\
\hline$s$ de seguridad & 90 & 10 & $-s+x-1$ & 93 & 25 & 95 & 128 & 861 & 1463 & 22 & 60 & 66 & 13 & 15 & 91 & 87 & 741 & 127 & 23 & 61 & 305 & $51 \quad 25$ & $25 \quad 54$ & $26 \quad 46$ & $\begin{array}{ll}6 & 17\end{array}$ & 64 \\
\hline 4. E & 68 & 32 & 128 & 82 & 78 & 89 & 285 & 542 & $20 \quad 61$ & 39 & 45 & 50 & 25 & 8 & 87 & 127 & 731 & 127 & 26 & 55 & 285 & 502 & $23 \quad 42$ & $25 \quad 45$ & 522 & 60 \\
\hline 5. E & 52 & 48 & 5 & 90 & is & 96 & I1 8 & 841 & 1569 & 29 & 60 & 54 & 29 & 58 & $87 \quad 1$ & 147 & 761 & 117 & 22 & 64 & $28 \quad 5$ & 522 & $20 \quad 46$ & $20 \quad 53$ & $\begin{array}{ll}3 & 17\end{array}$ & 67 \\
\hline I Nava. & 26 & 26 & 13 & 48 & 8 & 74 & 85 & 521 & $17 \quad 13$ & 18 & 19 & 23 & 9 & 10 & $78 \quad 1$ & 134 & 43 & 84 & 13 & 16 & 142 & $27 \mathrm{~d}$ & $16 \quad 15$ & $13 \quad 32$ & 214 & 36 \\
\hline 7. El P & 29 & 55 & 37 & 52 & 17 & 773 & 375 & 567 & $74 \quad 15$ & 45 & 36 & 35 & 28 & 29 & 69 & 265 & $58 \quad 1$ & 195 & 737 & 34 & 343 & $\begin{array}{ll}37 & 36\end{array}$ & $\begin{array}{ll}36 & 26\end{array}$ & $\begin{array}{ll}33 & 31\end{array}$ & 140 & 39 \\
\hline 8. El C & 29 & 55 & 335 & 591 & 158 & 803 & 365 & 567 & $\begin{array}{ll}75 & 15\end{array}$ & 42 & 42 & 33 & 29 & 15 & 762 & 285 & 592 & 215 & 39 & 41 & 363 & $35 \quad 3$ & $\begin{array}{ll}38 & 28\end{array}$ & $\begin{array}{ll}34 & 31\end{array}$ & 140 & 41 \\
\hline 9. Su & 32 & 58 & 50 & 443 & 36 & 595 & 54 & $46 ?$ & $70 \quad 20$ & 49 & 36 & 42 & 16 & 14 & 67 & 364 & 463 & 344 & 644 & 43 & $\begin{array}{ll}38 & 3\end{array}$ & $34 \quad 4$ & $46 \quad 21$ & $39 \quad 31$ & 147 & 35 \\
\hline 0 & 90 & 10 & 1 & 92 & 2 & 94 & 15 & 95 & 668 & 9 & 70 & 35 & 29 & 3 & 83 & 17 & 74 & 56 & 33 & 69 & 96 & 61 & 840 & 1346 & & 67 \\
\hline 11. $E \mathrm{~F}$ & 13 & 87 & 93 & 34 & 46 & 528 & 802 & 202 & $28 \quad 46$ & 20 & 42 & 8 & 59 & 48 & 43 & 34 & 413 & 30 & 45 & 21 & $25 \quad 3$ & $\begin{array}{ll}37 & 22\end{array}$ & 22 2I & $29 \quad 30$ & $0 \quad 36$ & 37 \\
\hline & 17 & 81 & 39 & 54 & 93 & 5 & 49 & 46 & $12 \quad 75$ & 37 & 56 & 3 & 66 & 63 & 28 & 294 & 452 & 28 & 20 & 50 & 135 & 501 & $14 \quad 29$ & $\begin{array}{ll}19 & 41\end{array}$ & 127 & 46 \\
\hline & 3 & 97 & 26 & 63 & 12 & 817 & 792 & 21 & 765 & 34 & 43 & 6 & 69 & 27 & 59 & 10 & 601 & 14 & 322 & 48 & 164 & $48 \quad 1$ & $14 \quad 28$ & 1244 & 416 & 54 \\
\hline 14 & 71 & 29 & 21 & 71 & 118 & 881 & 16 & 808 & $81 \quad 11$ & 31 & 49 & 37 & 36 & 48 & 88 & 166 & 631 & 11 & 434 & 47 & 293 & $\begin{array}{ll}39 \quad 2 \\
\end{array}$ & $21 \quad 28$ & $30 \quad 28$ & $8 \quad 35$ & 44 \\
\hline & 13 & 87 & 28 & 64 & 18 & 817 & 712 & 293 & 3046 & 82 & 12 & 30 & 53 & 8 & 83 & 175 & $58 \quad 1$ & 13 & & 36 & 313 & $37 \quad 2$ & $20 \quad 30$ & 2138 & $8 \quad 30$ & 46 \\
\hline 16. UCD & 61 & 39 & 2 & 95 & 1 & 98 & 1 & 99 & 1368 & 12 & 72 & 63 & 21 & 4 & 85 & 67 & 76 & 17 & 212 & 64 & 135 & 55 & $\begin{array}{ll}743 \\
\end{array}$ & $13 \quad 46$ & 610 & 67 \\
\hline & & & & & 519 & & 108 & & 1.106 & & 501 & 15 & 158 & 11 & 13 & 347 & 47 & 399 & & 249 & 509 & & 509 & 473 & & 389 \\
\hline
\end{tabular}

* Los porcentajes esian calculados horizontalmente dentro de cada clicntela electoral sobre el total de efectivos que figura al pie de cada columia, hubjendo eliminado en caja caso el NS/NC. La última columna pertenece a la muestra conjunta de la Comunidad Autonoma. 
En el electorado AP destaca su autocomplacencia en la propia poítica del partido $(90 \%)$, su alto apoyo a las fuerzas de seguridad del Estado $(90 \%)$, a las fuerzas armadas $(87 \%)$, al rey $(81 \%)$, al PNV (71 \%), al Parlamento español $(68 \%)$, a UCD $(61 \%)$ y al propio Gobiemo español $(52 \%)$. Por el contrario, destaca su rechazo del PCE (97\%), del PSOE $(87 \%)$, de EE $(87 \%)$, de HB $(81 \%)$, de la política municipal (58\%) y del Patlamento y Gobierno vascos $(55 \%)$. Es un electorado clatamente distanciado de las actitudes medias del conjunto de la pobiación.

El electorado de EE solamente valora positivamente su propia política $(93 \%)$ y la municipal $(50 \%)$; en el resto de los casos la tendencia predominante es negativa para UCD (95\%), para las fuerzas de seguridad (93\%), para el ejército ( $92 \%$ ), para AP (92\%), para el Gobierno español $(90 \%)$, para el Parlatmento español (82\%), para el PNV (71\%), para el PSOE (64\%), pata el PCE (63\%) y, en menor medida, para el Gobierno vasco $(59 \%)$, HB (54\%) y el Parlamento vasco $(52 \%)$. Hay que destacar que este electorado se divide en partes iguales a favor (45\%) y en contra ( $44 \%$ ) del rey y que, a pesar de todo, una proporción mayor que el promedio ve con buenos ojos a HB (39\%) y PCE (26\%). Es un electorado que se aleja significativamente del promedio de valoraciones del conjunto de la muestra.

Situación más drástica es la de $\mathrm{HB}$ que, salvo su propia autovaloración positiva (93\%) y la que hace de EE (46\%), se caractetiza por superar en negatividad a todos los demás en todas las instituciones: UCD (98\%), Gobierno español (96\%), fuerzas de seguridad (95\%), AP (94\%), ejér. cito (91\%), Parlamento español (89\%), PNV (88\%), PSOE y PCE (81\%), Gobierno vasco $(80 \%)$, Parlamento vasco $(77 \%)$, Parlamento Foral Navarro (74\%), el rey $(73 \%)$, la propia política municipal $(59 \%)$ y, pot último, EE (52\%). Se trata, por tanto, de un electorado alejado del perfil actitudinal de la problación vasca en su conjunto.

El electorado comunista valora positivamente, alejándose de los valores medios, a EE ( $80 \%$ ), a su propia política (79\%), al PSOE (71 \%), la política municipal $(54 \%)$ y al propio $\mathrm{HB}(49 \%)$. Sin embargo, supera las valoraciones negativas medias en los casos de UCD (99\%), AP (95\%), de las fuerzas de seguridad ( $86 \%)$, del Gobiezno español ( $84 \%)$, del PNV $(80 \%)$ y del ejército $(79 \%)$ y, en menor medida, del Gobierno y Parlamento vascos $(56 \%$ ) y de la política municipal (46\%). El rey tiene para este electorado una imagen menos positiva $(50 \%)$ que para el conjunto de la población, al contrario que el Parlarnento español, cuya valoración positiva supera en un $+6 \%$ al conjunto de la muestra.

El electorado PNV destaca por su autocomplacencia (82\%), por la valoración del papel real (72\%), del Parlamento (74\%) y del Gobierno 
(75\%) vascos y de la política municipal (70\%), en las que ellos son protagonistas directos. Sobresale su rechazo de HB (75\%), PCE $(65 \%)$ y EE $(46 \%)$ por encima del promedio, estando el de las instituciones y partidos estatales en torno al $60 \%$ como el promedio general.

EI electorado del PSOE, además de valorar positivamente su política ( $82 \%$ ), to hace del rey $(76 \%)$ y tiende a ver con mejores ojos que el conjunto de la población a los ayuntamientos (49\%), al Parlamento vas. co $(45 \%)$, al Parlamento español (39\%), al PCE (34\%) y al ejército $(30 \%)$. Su rechazo es significativamente mayor que el promedio cuando se habla de UCD (72\%), de HB (56\%) y del PNV (49\%), aunque en términos absolutos los rechazos de AP $(70 \%)$, del Gobierno español $(60 \%)$, de las fuerzas de seguridad $(60 \%)$ y del ejército $(53 \%)$ sean mayores.

En UCD destaca la alta proporción de desorientados que tho emiten un juicio en muchas de las instituciones, así como su menor autocomplacencia (63\%), si se la compata con la del resto de los partidos. Sobresalen las valoraciones positivas del rey ( $89 \%$ ), de las fuerzas de seguridad $(66 \%)$ $y$, con menor entusiasmo, del ejército (59\%), del Gobientı (54\%), del Parlamento $(50 \%)$ y del propio AP (35\%). Hay que hacer notar la alta proporción de rechazo del PCE $(69 \%)$, de HB (66\%), de EE (59\%) y del PSOE $(53 \%)$. Sin embargo, la situación es más ambigua al valorar las instituciones autonómicas y al PNV, siendo mayor la aceptación que el techazo, si bien un tercio de los electores no responde.

Si ahora nos fijamos en el perfil electoral de la legitimación de las instituciones, tenemos las siguientes situaciones:

- E1 rey tiene sus mejores valedores en los electorados de UCD, AP, PSOE y PNV; en menor medida, entre la población que se abstiene, los jóvenes que no han podido votar, el electorado comunista, dividiéndose en dos el de EE. Por el contrario, sus detractores se condensan especialmente en los electorados de HB y de la izquierda extraparlamentaria.

- Las instituciones del Estado (ejército, fuerzas de seguridad, Parla. mento y Gobierno) encuentran sus apoyos mayores en los electorados de AP y de UCD. Por el contrario, el techazo procede, sobre todo, de HB, izquierda extraparlamentaria, EE, PCE, la juventud que no ha votado, parte importante de la abstención y, en menor medida, del PNV y el PSOE.

- Por fin, las instituciones autonómicas sólo encuentran apoyo significativo en el PNV, mientras que el rechazo es claro en $\mathrm{HB}$, izquierda extraparlamentaria, juventud, abstencionistas, PCE, EE y AP. El PSOE y UCD en este punto se dividen entre el apoyo y el rechazo. 
- Sin embargo, son los ayuntamientos les que recogen mayoría de adhesiones heterogéneas, sin demasiado entusiasmo, en los electorados del PNV, PCE, EE, PSOE y UCD. Concentrándosc: los detractores en los extremos: $A P, H B$ y la izquierda extraparlamentaria.

Concluyendo, diremos que lo que más llama la atención al analizar el juicio que nuestros ciudadanos hacen de las principales instituciones políticas es el predominio casi sistemático de las opiniones negativas sobre las positivas, indicador evidente de la crisis de legitimación que nos afecta o del llamado, vulgarmente, «desencanto» o «cansancio». Es de subrayar, por otra parte, que la única institución que arrastra el favor de la población sea el rey, sin duda por la imagen que se ha ganado de «garante» de la democracia, el futuro, etc., y por presentarse al margen de la política diaria. Detrás de esto hemos de sospechar que existe una línea de legitimación sociológica cuasicarismática y simbólica que no puede responder más que a una necesidad política muy extendida de «ilusión colectiva». Por otra parte, la irmagen de las instituciones gana favor a medida que éstas están más cercanas a la población, quizá por un efecto de que determinados sectores de la misma se sientan más protagonistas de unas que de otras.

\section{e) LA ACTITUD ANTE ETA}

Fijándonos ahota en la procedencia electoral de los que manifiestan una opinión de apoyo explícito a ETA, resulta la siguiente distribución: el $44 \%$ son electores de $\mathrm{HBB}$, el $10 \%$ de EE, el $8 \%$ se han abstenido por razones políticas y otro tanto no manifiesta su opción electoral, el $7 \%$ han votado alguno de los dos partidos de la izquierda radical, un $6 \%$ al PNV, un $5 \%$ no han votado por no tener la edad y otro tanto por imposibilidad o no saber qué hacer y, por último, un $2 \%$ ha votado al PCE o al PSOE.

Mucho más igualada es la distribución de la procedencia electoral de los que justifican las acciones de ETA: el $15 \%$ pertenecen a electores de HB y PNV, el $17 \%$ no ha declarado su opción electoral, el $13 \%$ son electores del PSOE o del PCE y otro tanto son jóvenes que no han podido votar, un $12 \%$ son electores de EE, un $7 \%$ se ba abstenido por razones políticas y un $5 \%$ ha votado por alguno de los partidos minoritarios de izquierda.

$\mathrm{Si}$, por el contrario, nos fijamos en la procedencia electoral de los que manifiestan una opinión de rechazo frontal a ETA, resulta la siguiente distribución: el $30 \%$ procede del PNV, el $23 \%$ de los que no declaran su 
opción electoral, el $13 \%$ del PSOE, el $9 \%$ de los que se han abstenido por tazones no politicas, el $8 \%$ de electores de UCD, los electores del PCE, EE y los que se han abstenido por razones políticas alcanzan el $3 \%$ respectivamente y los $\mathrm{HB}$ y los que no han podido votar por no tener la edad llegan al $2 \%$.

Resumiendo, finalmente, el perfil ideológico de las distintas opiniones a partir de los promedios de las dos escalas de regionalismo/nacionalismo y derecha/izquierda, tenemos la siguiente tabla:

\section{TABLA 10}

Promedios de las escalas de regionalismo y derecha/izquierda de las opiniones ante ETA

\begin{tabular}{lcc}
\hline Opiniones & Esc. Reg./Nac. & Esc. Derecha/Izquierda \\
\hline Apoyo total & 7,5 & 7,9 \\
Justifican & 6,9 & 7,1 \\
Fines sí & 6,8 & 6,6 \\
Regular & 5,8 & 6,5 \\
Antes sí & 6,5 & 6,6 \\
Indiferentes & 5,6 & 6,9 \\
Miedo & 6,3 & 6,4 \\
No violencia & 5,8 & 6,1 \\
Terroristas & 5,1 & 5,1 \\
Rechazo total & 5,8 & 5,7 \\
NS & 5,4 & 6,2 \\
NC & 6,3 & 6,4 \\
\hline
\end{tabular}

Si el apoyo explícito a ETA se sitúa en un promedio de nacionalisno e izquietda radical, la justificación responde a un nacionalismo convencido y a una posición moderada de izquierda, situándose el resto de las opiniones en una posición promedio de izquierda moderada y centroizquierda, si bien los que justifican los fines y daban su apoyo a ETA anteriormente definen un nacionalismo convencido y el resto de las opiniones oscilan entre pro. medios de regionalismo y nacionalismo más o menos convencidos. 
Aunque no disponemos para Navarra de datos equiparables a los anteriores, sin embargo los tenemos mucho más recientes (referidos a las últimás elecciones generales de 1982) y, en todo caso, útiles para calibrar el distanciamiento ideológico-político en el electorado navarro.

En primer lugar, podemos observar la distribución de los principales electorados de 1982 según su autoubicación en una escala de tendencia politica, tal como mostramos en la tabla 11.

Es constatable la ubicuidad y la falta de nitidez ideológica de los distintos espacios políticos, to cual explica la gtan movilidad electoral habida hasta ahora y la falta de cristalización del sistema de partidos navarros. Por otra parte, si nos fjamos en el porcentaje de no ubicados, veremos la debilidad competidora de las opciones centristas frente a la mayor nitidez ideológica de las opciones colaterales y extremas.

Con todo, una simple aproximación óptica nos permite identificar las posiciones promedio de los distintos electorados; así, UPN ocupa el espacio de la derecha, UCD el centro-derecha, CDS y PNV una posición intermedia entre el centro y el centroizquierda, PSOE una posición a caballo entre el centro-izquietda y la izquierda, $E E$ la izquierda y $\mathrm{HB}$ a caballo entre ésta y la extrema-izquierda.

Sin embargo, el principal caballo de batalla en Navarra y la fuente de mayor distanciamiento político es el contencioso Navarra/Euskadi, ligado a la cuestión nacional vasca. Si nos fjamos en la posición mantenida por estas clientelas respecto a la integración o no integración de ambas comunidades, Autónoma del País Vasco y Foral de Navarra, tenemos la tabla 12.

Como vemos, este indicador aporta mucha más nitidez al espectro político, si tenemos en cuenta que es mínimo el nivel de NS/NC. Por otra parte, distancia claramente a los electores del centro y la derecha y algo menos a las opciones nacionalistas, ocupando el electorado socialista una posición intermedia. Lo más patadójico, sin duda alguna, es el nivel de no integracionismo (uno de cada cinco) que existe en las principales opciones nacionalistas, tanto la moderada (PNV) como la tadical (HB). 
«Papers»: Revista de Sociologia

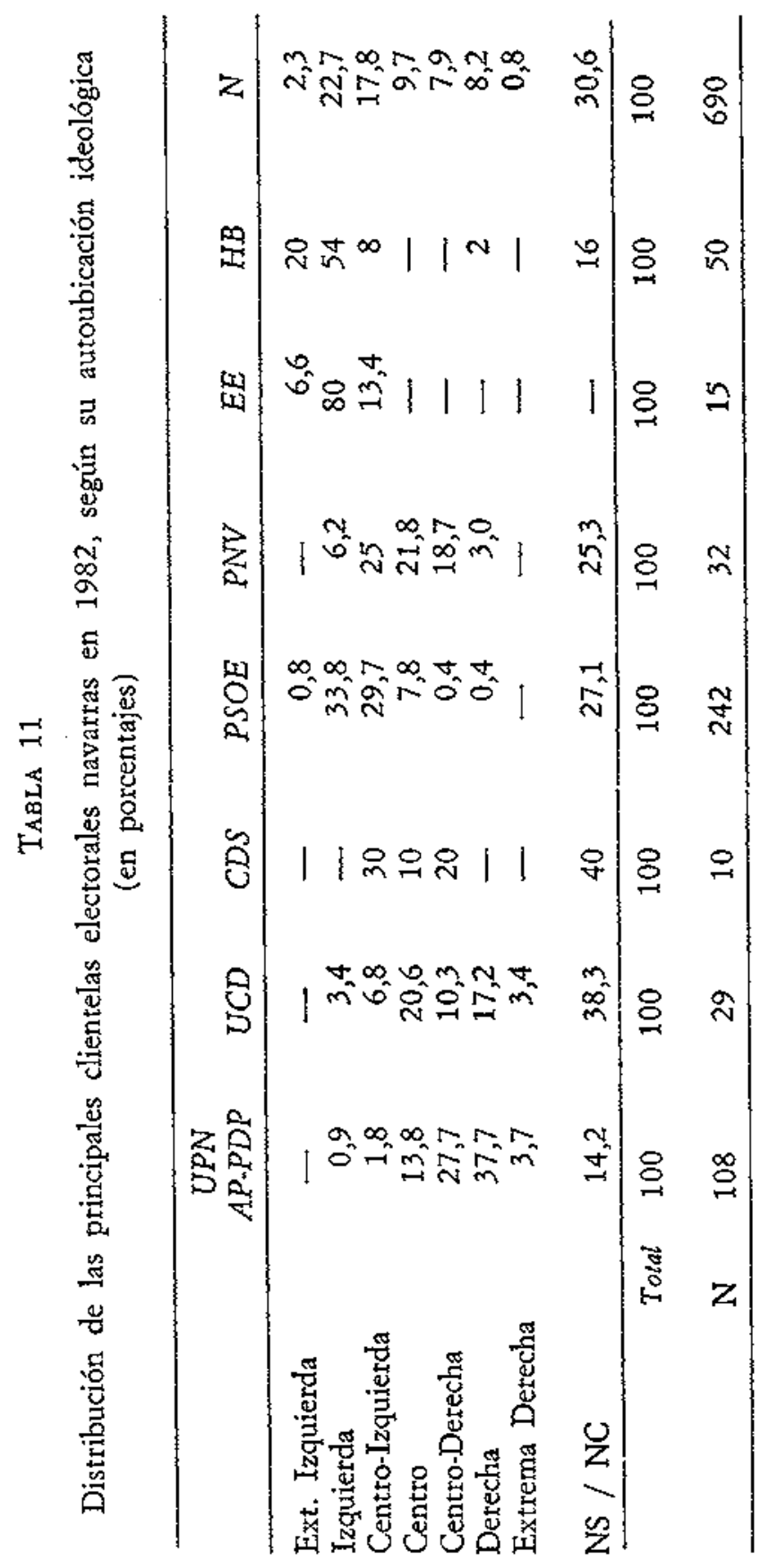


La estructura política vasca en 1983

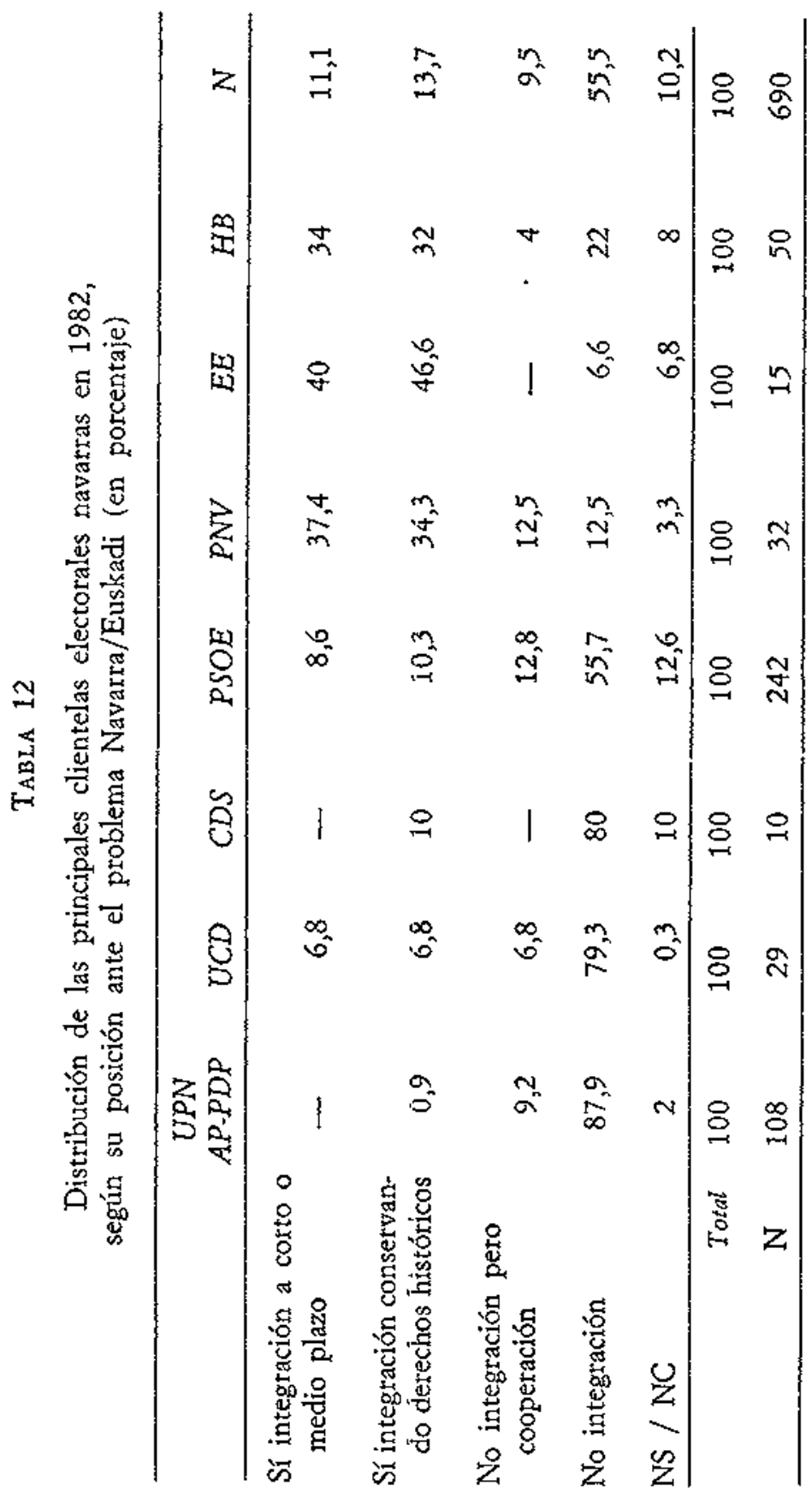


«Papers»: Revista de Sociologia

\section{CONCLUSIONES: ALGUNAS CLAVES INTERPRETATIVAS DE LA DINAMICA POLITICA VASCA}

Después de este análisis descriptivo, se hace necesario deducir las conclusiones más relevantes que puedan aportarnos algunas claves explicativas de la dinámica política vasca. Por esta razón, este capítulo de conclusiones está dividido en cuatro apartados que se refieren, respectivamente, a la segmentación política de la sociedad vasca, al pluralismo extremado de nuestro sistema de partidos, a la masif́cación del comportamiento político vasco y a la crisis de legitimación de la estructura política vasca.

1. LA SOCIEDAD VASCA ES UNA SOCIEDAD POLÍTICAMENTE SEGMENTADA

La agresividad creciente de las campañas electorales, el desmadre de descalificaciones, totalizaciones simplistas y exclusivismos estigmatizantes contenidos en el lenguaje de los políticos, la guerra sucia desatada, explícita - implícitamente, por determinadas opciones políticas y sus medios de expresión, la violencia, su reptesión y la dinámica antirrepresiva que generan, son algunos de los indicios más relevantes de la precatia articula ción política de nuestra sociedad.

Sin duda alguna, el elemento más visible de esta segmentación es, además de la propia fragmentación electoral, la dificultad de concluir pactos y formar mayorías estables en las instituciones, los portazos, esporádicos o permanentes de casi todas las fuerzas políticas a determinadas instituciones, etcétera, debido a que el distanciamiento ideológico y político entre las distintas opciones es realmente complicado. Los que están más distantes en una dimensión están a partir un piñón en otra y viceversa, sea por profundas razones sociológicas (origen, lengua, clase social, medio rural o urbano, etc.), sea porque ideológica o simbólicamente lo estén o, sencillamente, por el principio de oposición y arrinconamiento políticos de una determinada opción.

Las coordenadas del distanciamiento político vasco son claras y definen un sistema de oposiciones casi maniqueas: nacionalismo frente a estata. lismo, derecha frente a izquietda, aceptación de las instituciones frente a radicalismo antisistema y política represiva frente a lucha antirrepresiva. Junto a estos pares de oposiciones básicas aparecen en nuestro discurso político de forma recurtente una serie de dualismos exciuyentes que enconan las relaciones políticas hasta hacerlas casi imposibles, asi: en la primera coordenada, de la simple referencia al ámbito vasco o español de la 
acción política se pasa a la lectura vasquismo/anti-vasquismo, vasquismo/ españolismo e independentismo/centralismo, que, poco a poco, cortocircuitan el entendimiento político por el recurso a las esencias y a las identidades simbólica y emocionalmente sentidas; en la segunda coordenada, del recurso al tono conservador o progresista de los programas políticos y de los intereses socio-económicos se pasa a las oposiciones autoritarismo/ toletancia, franquismo/antifranquismo, reformismo/rupturismo, que defrlen uno de los atavismos sociales de nuestro entorno; en la tercera coordenada, de la fluidez entre reforma o revolución se pasa al techazo frontal 1) larvado del sistema institucional (el Estatuto, la Constitución, etc.) o a su defensa a ultranza, a la violencia como única vía de cambio social o al parlamentarismo y la democracia delegada de las mayorías mecánicas como única vía de participación y decisión políticas; finalmente, la cuarta coordenada define todo un sistema de oposiciones en torno al aspecto más atávico de nuestra estructura política como es la dinámica social de la violencia: los múltiples aspectos de la represión institucional e histórica, las guerras civiles y la respuesta de la acción directa, las alternativas ante la pacificación y la lucha antirrepresiva que generan. No hay tétminos medios, hay muy pocos puentes en nuestra sociedad. Lo más grave, sin embargo, de esta segmentación política es la impregnación de este lenguaje en la vida cotidiana de nuestra sociedad civil.

No es posible aquí recopilar y sistematizar este tipo de discurso, pero ilustraciones palpables del mismo las encontramos, sobre todo en estos últimos meses, en editoriales, artículos, declaraciones, mitines, movilizaciones, campañas y mociones políticas que animan diariamente la vida cotidiana de la sociedad vasca.

Por otta parte, lo que sucede en el Parlamento vasco y en los ayuntamientos, lo sucedido en el Parlamento Foral Navarro, la continua dialéctica Vitoria-Madrid, los avatares de la llamada «mesa por la paz», el tema de las negociaciones para el abandono de la lucha armada y la salida de los presos, la formación de pactos en las instituciones, el plan ZEN, el tema del euskera y de las ikastolas, la LOAPA, etc., son chispazos en los que salen a la luz todas las contradicciones de ese discurso y esas relaciones políticas tan complejas (como botón de muestra recuérdese lo sucedido en el Ayuntamiento de Bilbao en la anterior legislatura, o lo sucedido recientemente en el de Irún, o el tema de las banderas iniciado en Rentería o la discusión en el Parlamento vasco de la normativa de elecciones para las Juntas Generales).

Con todo, la coordenada nacionalista con sus múltiples círculos concéntricos sigue catalizando la vida política del país y el PNV, su expresión más genuina, sigue aglutinando al segmento más persistente de nuestro 
electorado. Además, si observamos la última campaña electoral, él y su sintonía han sido los que han distribuido el juego dialéctico. Y to solamente esto, sino que en el entramado de las combinaciones pata formar mayorías institucionales y pata tomat decisiones en estos cuatro años, el PNV, desde su coordenada principal catalizará el alineamiento de las otras coordenadas, consiguiendo el apoyo explícito o implícito de los dos polos opuestos del sistema de partidos en la CAV y se exigirá en árbitro en Navatra.

\section{UN SISTEMA DE RARTIDOS CARACTERIZADO POR EL PLURALISMO POLARIZADO}

Esta segmentación política de nuestra sociedad se concreta en una cristalización precaria de nuestro sistema institucional, que lleva parejos dos procesos más profundos: una quiebra en el sistema de legitimación y una desarticulaciót de las telaciones socio-políticas y, consecuentemente, una integración precaria de la sociedad civil vasca, que, por otra parte, lucha denodadamente por recuperar o construir su identidad colectiva. Lo que más resaita en la estructura electoral del País Vasco, con respecto a las sociedades occidentales, es la intensidad sociológica y política de la distancia ideológica en el sistema de partidos. Es evidente que esta distancia ideológica se debe, sobre todo, a la beligerancia independentista e izquierdista del que del 79 al 82 fuera el primer partido de la oposición de la CAV y la principal opción nacionalista en Navarra (HB).

Como ya se ha indicado, siguiendo a $\mathrm{G}$. Sartori, se puede caracterizar el sistema de partidos vasco como altamente fragmentado y polarizado. Lo grave en un sistema de partidos no es su fragmentación, sino su polatización, y ésta en nuestro caso depende:

1. De la fractura entre dos focos de distanciatniento ideológico fuerte: las demandas autonómicas (o las cotas institucionales para la reproducción y la recomposición de la identidad colectiva) y la defensa de un programa social más o menos revolucionario o radical.

2. Del arraigo y consistencia de la opción u opciones del centro geométrico del sistema frente al impacto deslegitimador de las opciones antisistema o de chantaje.

3. De la contraposición cada vez más radicalizada de dos estrategias para imponer los intereses y voluntad política tespectivos: el a-institucionalismo o anti-institucionalismo más o menos viclento y el parlamentarismo estatutario más o menos convencido. 
En esta situación asistimos en Euskadi a la construcción de dos comunidades políticas que se rigen cada vez más por pautas de lo que Sartori llama "política de superoferta», o de promesas excesivas y grandes gestos que denotan una falta de arraigo y una inseguridad en la legitimación sociológica de las respectivas posiciones y del propio sistema institucional en construcción, en lugat de seguir en las coordenadas de una política competitiva.

Los altos niveles de fragmentación y polarización de nuestro sistema de partidos son relevantes, tanto respecto a la formación de coaliciones y mayorias como a otros aspectos de la vida política, tales como los problemas más genéricos de la legitimación.

De cara al futuro, pasando de la consideración de los problemas y posicionamientos de los aparatos y líderes de los partidos al comportamiento práctico de sus partidarios y electores, la cuestión fundamental a dilucidar es si los partidos compiten a lo largo de una dimensión primaria izquierda/ derecha o, por el contrario, es su competición irremediablemente multidimensional. Esta última parece ser precisamente la característica del sistema de partidos vasco, al menos en el área de identificación entre las opciones electotales y sus partidarios más fieles.

En estos segmentos sociológicos y en esta área de identificación se superponen básicamente dos dimensiones: la dimensión izquierda/derecha y el conjunto simbólico de la dimensión etnolingüística, que en unos casos funcionan como tensiones cruzadas que se neutralizan y en otros como tensiones acumulativas que se refuerzan entre sí.

Si nos atenemos a los contingentes sociales electoralmente activos, en esta área de identificación, sin poder afirmar en absoluto que haya desapa. tecido de los mecanismos de identificación la dimensión primaria izquierda/ derecha, parece que ésta sufre una profunda mediatización por parte del discurso nacionalista, pero no en un único sentido, sino en sentidos diversos.

En el área de competición, sin embargo, los datos sobre movilidad electoral, localización sociológica de la misma y desmovilización masiva de electores no identificados, o con fidelidades precatias, el funcionamiento de tal mixtura de dimensiones será radicalmente distinto.

Esto hace que en la estructura de la competencia partidaria del sistema de partidos vasco nos encontremos clatamente con dos dinámicas telacionadas con lo antes dicho: expansiva una (PNV, EE y, en menor medida, $\mathrm{HB}$ en la CAV) y defensiva la otra (coalición y PSOE fundamentalmente), cuya resolución (sostenimiento, retroceso o progresión) no es previsible a medio plazo.

Estas y otras consideraciones sitúan la diferencialidad del sistema de 
partidos vasco, en cuanto al comportamiento del mercado político, en un nivel tipológico compartido por casos como el belga (sistema flamenco) o el canadiense (sistema quebecois) por citar alguno, lo cual obliga a la ciencia y a la sociología políticas a repensar la precariedad, o cuando menos no absolutez, de los marcos exclusivamente estatales de comprensión y caracterización de los mercados políticos.

\section{LA MASIFICACIÓN DEL COMPORTAMTENTO POLÍTICO}

EN EL SENO DEL DUALISMO QUE SIGUE ENFRENTANDO A LA SOCIEDAD TRADICIONAL Y A LA SOCIEDAD INDUSTRIAL

Para los sociólogos que han teorizado sobre este punto, los cambios rápidos en la pirámide estratificacional, el desarraigo comunitatio, la anomía en las relaciones sociales, la pérdida de identidad colectiva, la contraposición agto/ciudad y la concentración de poder en minorías oligárquicas generan los fenómenos propios de una sociedad de masas y de un comportamiento político masificado, cuyas características más televantes son las siguientes: 1) fuerte contraposición de modelos simbólicos y culturales; 2) burocratización y tecnocratización del dominio de los políticos cada vez más alejados y por encima de las masas; 3) aparición de partidos de aluvión, movimientcs sociales y contingentes sociales inhibidos políticamente con difuminadas fronteras de clase; 4) una legitimación política permanentemente precaria por la alienación y violencia políticas que padecen las masas en base a la existencia de mitos totalizantes y a la búsqueda de sumisión.

En la sociedad vasca actual, en la medida en que se han producido la mayor parte de los fenómenos estructurales apuntados y en la medida en que la mayor parte de la población está concentrada en las áreas metropolitanas, se puede hablar también de la existencia de un comportamiento político masificado con características peculiares: por una parte, unas masas despolitizadas y de aluvión y, por otra parte, unas masas ansiosas de identificación comunitaria y con una mística de partido y de acción. En uno y otro supuesto las fronteras de clase están difuminadas.

Parece obvio que esta perspectiva de la masificación del comportamiento político hay que introducirla a la hora de tratar de explicar los procesos de nacionalización, radicalización y desmovilización políticas que han caracterizado el comportamiento político de nuestra población.

$\mathrm{Si}$ la expresión «sociedad masa» viene a significar pata los sociblogos un mundo amorfo e inestructurado, el concepto de «masificación» se refiere al proceso por el cual la sociedad, total o parcialmente, se convierte en masa. 
Efectivamente, en las crisis autoritarias de nuestro siglo las «masas amorfas» surgieron de clases medias nuevas en transición, ejércitos desmilitarizados, desempleados inquietos y trabajadores empobrecidos. Se trata, pues, de colectividades sin rumbo, de individuos y estratos inseguros y despersonalizados, pero con una fuerte ansiedad de identidad colectiva.

De este modo, en Euskadi, especialmente en las zonas metropolitanas e industriales, se dan las precondiciones para la aparición de los fenómenos característicos de la «sociedad masa», así:

1. La secundarización y terciarización de la actividad económica y de la fuerza de trabajo han producido tápidos cambios en la pirámide estratificacional, con una aparente igualación social en determinados sectores.

2. La avalancha migraforia, tanto externa como interna, ha producido un desartaigo comunitario, social y cultural, con una fuerte anomía en las relaciones sociales.

3. Los efectos materiales y subjetivos de la oligatquización de nuestro Estado (CME) han sido especinlmente sensibles en el modelo de acumulación industrial seguido en Euskadi, al igual que lo han sido los efectos sociales y políticos de la específica lucha de clases protagonizada por nuestra sociedad.

4. La contraposición de modelos simbólicos y cultutales ha hecho perder la identidad colectiva a contingentes importantes de la población vasca, generando la tespuesta defensiva de sectores sociales muy diversos.

5. Por otra parte, se observa, tanto en las acciones parapolíticas como en los estudios muestrales, un alejamiento progresivo entre las masas y los dirigentes políticos, especialmente con respecto a la buroestructura y tecnoestructura del Estado, una vez desarticulada la red de relaciones y agregados sociales primarios.

6. Consecuentemente, la voluntad política se habrá de encauzar fundamentalmente a través de los "partidos de alurvión» y de los «movimientos sociales», cuyas fronteras estratificacionales y de clase son difíciles de delimitar.

7. El resultado es una alienación política sin precedentes y una variada violencia politica.

8. Finalmente, nos encontramos en la estructura simbólica de nuestro sistema y nuestro comportamiento político con la existencia de mitos totalizantes y la búsqueda de sumisión, cuyos indicadores son los siguientes: 1) la fuerza del "partido de masa» se basa en la «necesidad de comunidad» y en la «necesidad de confotmidad y sumisión» de las propias masas desarraigadas (cfr. R. Nisbet); 2) las falsas relaciones comunitarias de los partidos y organizaciones activistas, etc. (engtanajes jerárquicos y burocráticos 
de una misma máquina sociológica) tesponde a una «mística de partido»; 3) los movimientos de masas, por otra parte, deben de satisfacer la «sed de creencias firmes» de la población (cfr. Sorel y Manheim); 4) el autoritarismo subyacente en las masas se basa en la «necesidad de jerarquía y otdens (cfr. Reich y Adorno).

De este modo, la cristalización política precaria se sitúa en una sociedad civil desarticulada por una progresiva masificación y privatización o atomización de las relaciones sociales en la vida cotidiana. Pero, a la vez, tal falta de cristalización acelera y contribuye a la reproducción de tal desarticulación, con lo que se dificultan enormemente los procesos de legitimación, pacificación y normalización políticas de nuestra sociedad.

Por el contrario, funcionan todavia en la parte más activa de nuestra sociedad otros mecanismos contradictorios con esta dinámica que podemos cifrar como: politización de la vida cotidiana, movilización política o parapolítica e identificación colectiva.

Este dualismo comportamental responde, por lo demás, al dualismo estructural latente en la sociedad vasca ante la falta de reciciaje de la sociedad tradicional por parte de la sociedad industrial en medio de la crisis política y cultural que dura ya más de un siglo.

\section{LA REMODELACIÓN DE LOS ESPACIOS POLÍTYCOS DESDE 1982 PUEDE RELANZAR LA LEGITIMACIÓN Y CLARIFICACION ROLÍTICAS}

El freno al desencanto (que no entusiasmo), que supone el récord de participación en las elecciones de 1982, por un lado, y la reciente sentencia del Tribunal Constitucional sobre la LOAPA, junto con la finalización de la transición autonómica, arraigan el modelo político, legitiman el modelo democrático y producen una clarificación política en ambas estructuras electorales y en los subsistemas de partidos de ambas comunidades autónomas.

La ligera mayoría de la izquierda en la CAV y en la CFN tomadas conjuntamente y la más ajustada mayoría de las opciones estatales en este mismo ámbito, tanto en 1982 como en 1983, transparentan más fielmente la realidad de la estructura social vasca. El equilibrio relativo que se pro. duce en el sistema de partidos tiene que suponer un cambio en las relaciones políticas entre los mismos, en la delimitación de los espacios políticos, en la política interna de dichas comunidades autónomas y hasta en sus recíprocas relaciones institucionales.

Efectivamente, la combinación de ambos subsistemas de partidos dan lugat a otro, en el que el PSOE y el PNV compiten por un tercio escaso 
de los votos válidos, seguidos de $\mathrm{HB}$ con el $14 \%$, de las fuerzas de centro derecha con un $17 \%$ en conjunto y de $\mathrm{EE}$ con un $7 \%$, en un equilibrio roto sólo por el mayor escoramiento del sistema hacia la izquierda en Navarra y hacia ei nacionalisno en la CAV.

Es ciento que la distancia ideológica to se ha reducido y que, aunque asistimos a un eclipsamiento relativo de la principal opción antisistema (HB), el bloque perdedor representado por la derecha no nacionalista también se ha fortalecido y radicalizado, especialmente en Navarra.

De todas formas, el cambio centrípeto producido en la CAV y la teducción de la fragmentación por efecto de la recuperación del partido del gobierno del Estado (PSOE) en 1982 y del ascenso constante del PNV pueden suponer un acercamiento del subsistema político vasco al sistema político español.

En Navarta también se ha producido, como hemos dicho, una clarificación política a caballo de la dinámica estatal de centrifugación del centro y de la dinámica vasca de afianzamiento del nacionalismo. Sin embargo, en el subsistema de partidos navarto el distanciamiento ideológico (UPN/HB) es aún mayor y más radical, habiéndose reforzado sus polos en una situación de alta fragmentación: por un lado UPN, la principal fuerza de la oposición conservadora y navarrista $y$, por otro, $\mathrm{HB}$, la principal fuerza nacionalista, que representa al tadicalismo violento. Las mayorías resultantes, la relativa reducción de la fragmentación y el reforzamiento de las opciones políticas con responsabilidades de gobierno en el Estado y en la CAV (PSOE y PNV) hacen prever una mejora en la gobernabilidad navarra si estas dos fuerzas políticas, ocupantes del centro geométrico del sistema de partidos, llegan a entenderse. 


\section{BIBLIOGRAFIA}

\section{Restauracion}

Corcuera, J.: Orígenes, ideologia y organización del nacionalismo vasco (1876 1904), Siglo XXI, Madrid, 1979.

Cillán Apalategui, A.: Sociología electoral de Guipuizcoa (1900-1936), Sociedad Guipuzcoana de Ediciones y Publicaciones, San Sebastián, 1975.

Estornes, I.: «Aproximación a un estudio de las elecciones y partidos políticos en Euskadi, desde 1808 hasta la Dictadura de Primo de Rivera», en la obra colectiva Historia del Pueblo Vasco, vol. 3, pp. 153-187, Erein, San Sebastián, 1979.

Mitalles, R.: Politica electoral en Vizcaya, 1890-1907, Memoria de Licenciatura, Universidad de Deusto.

\section{República}

Linz, J. y de Miguel, J. M.: Un análisis regional de las elecciones de 1936, en «REOP», núm. 48 (abri1-junio, 1977).

Tuseil, I. y García, G.: Introducción a la sociología electoral del País Vasco durante la II República, en «REOP», núm. 48 , op. cit.

\section{Transición}

Cámatá de Comercio de Bilbao: Clases sociales y aspiraciones vascas, Bilbao, 1979.

- Los vascos somos así, Bilbao, 1980.

Cibrián, R.: El sistema electoral y de partidos en Euxkadi, en «Papers», númeto $14(1980)$, pp. $69-98$.

Corcueta, J. y Garcia, M. A.: Sistema de partidos, instituciones y comunidad nacionalista en Euskadi, en «Revista de Politica compatada», núm. 2 (1980), pp. $155-190$.

Corcuera, J. y Pérez Calvo, A.: En torno al Referéndum del Estatuto de Autonomia del País Vasco. Notas sobre el subsistema de partidos vasco, en «Revista de EE. PP.», núm. 12 (noviembre-diciembre 1979), pp. 179-196. 
Davant, J. L.: Ipar Euskal herriko indar politikoak, en «Jakin», núm. 9 (eneromatzo 1979).

De Blas, A.: El Referéndum Constitucional en el País Vasco, en «Revista de EE. PP.», núm. 5 (noviembre diciembre 1978).

Garmendia, J. A. y otros: Abertzales y vascos, Akal, Madrid, 1982.

Harluxeta, K., Mimiague, P. y Tortealday, J. M.: Easkeal Herriko Botua Martxoko Hateskundeak, en «Jakin», núm. 11 (julio septiembre 1979), pp. 5-42.

Linz, J. y otros: Atlas electoral del Pás Vasco y Navarra, CIS, Madrid, 1980.

- Capítulo dedicado al País Vasco en el Informe Sociológico sobre el cambio politico en España (1975-1981), Euramérica, Madrid, 1981, pp. 509-539.

Liera, F.: «Estabilidad del sistema político e integración de Navarra y la Comunidad Autónoma Vascas, en la obra colectiva El Estado de las Autonomias: poder autonómico/poder central, CITEP, Madrid, 1981.

- Caracterización sociopolitica del sistema de partidos de la CAV y Navarra, en «Revista de EE. PP.», núra. 20 (marzo-abril 1981).

- Sociología electoral del País Vasco, Tesis Doctoral, Universidad de Deusto, 1980 (en catálogo en el CIS).

- Introducción a la Sociología electoral del País Vasco, en Estudios de Detusto, vol. $\mathrm{xxIx} / 2$ (julio-dicietnbre 1981), pp. 415-485.

- Comportamiento electoral y sistema de partidos en el País Vasco y Navarra en 1982, en «Revista de EE. PP.» (1983), en imprenta.

- Estructura social y comportamiento electoral en el País Vasco, IPES, Bilbao, 1983.

Núñez, L. C.: Base social de las candidaturas en las elecciones legislativas de 1977 en Guipuzcoa, en «Saioak», núm. 2 (1978).

- Euskadi Sur elcctoral, Eds. Vascas, San Sebastián, 1980.

Pérez Calvo, A.: Los partidos políticos en el País Vasco, Haranburu, San Sebastián, 1977.

- Partidos políticos y elecciones de 1980 en el País Vasco, en «Revista de EE. PP.", núm. 14 (marzo-abril 1980), pp. 169-194.

Rtriz Olabuenaga, J. I.: Geografía electoral de Guipúzcoa, en «Lurralde», número 1 (1978).

Talde: Euskadi ante las elecciones municipales, Eds. Vascas, San Sebastián, 1978.

Urrutia, V.: Elecciones generales en Navarra, en "Jakin", núm. extra Navarra desde Navarra (1978). 